\title{
MICROS EN SANTIAGO: DE ENEMIGO PÚBLICO A SERVICIO PÚBLICO*
}

\author{
Guillermo Díaz, Andrés Gómez-Lobo \\ y Andrés Velasco
}

Poner fin a los graves problemas que presenta el transporte público en Santiago (tiempos de viaje largos, congestión, inseguridad, alta tasa de accidentes, mala calidad del servicio, contaminación acústica y del aire), sostienen los autores de este trabajo, supone diseñar una regulación moderna que vaya más allá de las licitaciones de los años noventa, que hoy parecen agotadas. El Plan Transantiago propuesto por el gobierno, y que entrará en vigencia el 2005, parece apuntar en la dirección correcta. A la luz de un análisis de la manera en que opera el sistema de buses (micros) en Santiago, en este artículo se detallan algunos de los componentes que deberían formar parte de la

Guillermo Díaz. Subsecretario de Transportes.

ANDRÉs GómEZ-Lobo. Profesor del Departamento de Economía de la Universidad de Chile.

AndRÉs Velasco. Profesor de la Kennedy School of Government de la Universidad de Harvard.

* Agradecemos a Enrique Fernández, Henry Malbrán, Allan Thomas y Pablo Uribe por las entrevistas que nos concedieron. Las discusiones con José Gómez-Ibáñez fueron también muy útiles. Naturalmente, las opiniones vertidas en este artículo, así como los posibles errores de la información que contiene, son de nuestra exclusiva responsabilidad y no comprometen de manera alguna a las instituciones a las que pertenecemos.

Este trabajo aparecerá en el libro "Santiago: Dónde Estamos y Hacia Dónde Vamos", editado por Alexander Galetovic, que será publicado próximamente por el CEP. 
reforma del sector. Más que abandonar las licitaciones, se propone mejorarlas introduciendo más competencia, cambiando el método de cobro, induciendo un cambio en el perfil empresarial del sector y creando una red de recorridos más eficiente.

Chofer maneja malhumorado luego de cuatro horas de sueño (la bruja). Escolar sube medio dormido luego de tres (la pololita). Chofer lanza monedas por la ventanilla. Escolar dice improperios sin ningún recato.

Chofer detiene la máquina, insulta mejor que el muchacho. Escolar intenta avanzar hacia el fondo. Chofer saca barrote que oculta bajo el asiento (nunca se sabe con los delincuentes). Escolar saca navaja que lleva muy a mano (la gente está tan mala). Chofer golpea a escolar, escolar punza a chofer.

Gisela Watson, "Falta de Sueño", mención honrosa en el concurso "Santiago en 100 palabras", 2002.

\section{INTRODUCCIÓN}

$\mathrm{V}_{\mathrm{at}}$ arias encuestas han mostrado que el transporte público es uno de los servicios peor evaluados ${ }^{1}$. Las quejas más comunes apuntan a la agresividad de los choferes, la lentitud de los viajes y la inseguridad. Además de malo, el sistema parece difícil de reformar. Muchos santiaguinos han llegado a pensar que las micros ${ }^{2}$ — con su caos, congestión y contaminaciónson como la cordillera: inmutables. La percepción se debe a las dificultades que han enfrentado las diversas autoridades que han intentado transformar el sector.

Tal percepción es comprensible aunque inexacta. Los problemas del sistema de transporte público de Santiago son complejos pero tienen solución. Acerca de las soluciones técnicas hay un consenso creciente y transformar al sistema de transporte es posible políticamente. Así lo sugiere la experiencia reciente de Bogotá, Colombia, que tenía problemas similares a los de Santiago. Sin embargo, una reforma requiere enfrentar la oposición

${ }^{1}$ En la encuesta Solimare (Cruz, 2002), el transporte público obtuvo la segunda calificación más baja, después de los servicios municipales. La encuesta de calidad de servicios de ProCalidad y Adimark tomada a fines del 2002 muestra que el transporte público es el tercer peor evaluado entre 22 servicios (El Mercurio, miércoles 13 de noviembre, 2002, página B1).

${ }^{2}$ En Chile "la micro" es el apócope de "microbus", término que, a su vez, se refiere a bus de transporte urbano. (N. del E.) 
de parte del gremio de transportistas, que verá en ella una amenaza a las utilidades de las que hoy disfrutan.

No todo es malo con el sistema actual. Una virtud es su amplia cobertura: quien quiera cruzar Santiago y trasladarse desde Quilicura hasta Puente Alto o desde Maipú hasta La Dehesa, casi con seguridad encontrará un recorrido que lo recoja a pocas cuadras de su casa y lo deje cerca de su destino. Según la Secretaría Interministerial de Planificación de Transportes (Sectra), hoy en día solamente el $18 \%$ de los viajes requieren transbordo. A la cobertura se le suma la accesibilidad. Felipe Balmaceda (2004) muestra que más del $98 \%$ de los habitantes de Santiago vive a menos de ocho cuadras de un paradero de micros. Y según el Ministerio de Transportes (1997), un pasajero espera menos de cuatro minutos en promedio, por la alta frecuencia con que circulan las micros de cada recorrido, y también porque por las principales arterias circulan buses de varios recorridos.

Pero estas virtudes conviven con grandes defectos. Los tiempos totales de viaje son largos: muchos santiaguinos pasan dos o más horas al día trasladándose al trabajo o al colegio. En 2001 más del 50\% de los buses tenía ocho o más años, con la consecuente incomodidad e inseguridad para los pasajeros. Y la inseguridad se ve acrecentada por otros factores. Un sistema de transporte que estimula a que los choferes compitan en las calles por captar pasajeros - tal como ocurre hoy en Santiago- es una invitación a no respetar las leyes de tránsito y poner en peligro la vida de pasajeros y peatones. En 2001, en 7.392 accidentes ocurridos en la zona urbana de la Región Metropolitana estuvieron involucrados buses de la locomoción colectiva. De los 5.699 lesionados en esos accidentes, 112 murieron. No sorprende que el transporte público obtuviera una calificación de 11,9 puntos en una escala de 1 a 100 en una encuesta reciente, la segunda más baja, después de los servicios municipales, entre 19 servicios públicos evaluados ${ }^{3}$.

Y éstos son sólo los costos que los usuarios perciben directamente. Hay una serie de costos indirectos que el sistema le impone al resto de la ciudad. El más notorio es la contaminación: las micros tienen hoy la mayor responsabilidad relativa en la contaminación atmosférica en Santiago ${ }^{4}$.

Acaso tan importante, pero menos discutida, es la enorme contaminación acústica generada por el transporte público. Según Conama (2000), el aporte de los buses aumentó 20\% entre 1989 y 2000. En el año 2000 el

\footnotetext{
${ }^{3}$ Cruz (2002).

${ }^{4}$ Véase el capítulo XX de Ricardo Katz y Conama (2001).
} 
bus promedio generaba el ruido equivalente a 14,3 vehículos livianos. Sabido es que el ruido daña la salud, pero también tiene consecuencias económicas. Por ejemplo, un estudio reciente sugiere que reduce el valor de los bienes raíces. Bilbao et al. (2002) examinaron un barrio de Las Condes y concluyeron que el valor del arriendo aumenta en cerca de $\$ 28.000$ mensuales por cada 100 metros que un departamento se aleja de alguna calle ruidosa. Esto implica $\$ 336.000$ al año. Capitalizado a una tasa anual del $10 \%$, el valor es de $\$ 3,4$ millones por departamento en promedio ${ }^{5}$.

Los problemas del transporte público de Santiago combinan fallas de mercado y mala regulación. El primer defecto es que desaprovecha economías de escala que permitirían reducir los costos - tanto privados como sociales- del servicio de transporte. En la actualidad se superponen demasiados recorridos que congestionan las mismas avenidas centrales. Y los buses que circulan por vías con alta densidad de pasajeros, como la Alameda, son del mismo tamaño que los que circulan por la periferia. Esto no es óptimo si se quiere proveer los servicios de transporte al menor costo total.

La segunda falla ocurre dentro de cada línea. Los recorridos no son operados por empresas especializadas sino por asociaciones de dueños que compiten por los mismos pasajeros. Además, no hay mecanismos que permitan coordinar una frecuencia de circulación más baja ${ }^{6}$. La mala regulación tiende a magnificar estos problemas. Pareciera que las tarifas producidas por la última licitación son demasiado altas: la evidencia presentada en este trabajo muestra que la tasa interna de retorno de la inversión en un bus puede llegar a $27 \%$ en algunos recorridos. Con tasas de rentabilidad anormalmente altas, se estimula la oferta excesiva, cuyo resultado son demasiadas máquinas circulando semivacías.

La tercera falla distorsiona la relación entre los dueños de las micros y los choferes. A los choferes se les paga en efectivo una fracción de los boletos cortados. Aunque esto le conviene al dueño de un bus, socialmente es pernicioso porque ignora los costos que causa la competencia por pasajeros en la calle. Este problema tampoco lo puede resolver el mercado, ya que no resulta rentable para una empresa cambiar unilateralmente el sistema de remuneración cuando el resto paga por boleto cortado.

${ }^{5}$ En 2003 se aprobó una norma de ruido para los vehículos de la locomoción colectiva que debería reducir la contaminación acústica en el futuro.

${ }^{6}$ Un ejemplo es la práctica denominada "estrujar", según la cual el chofer que va adelante se retrasa un par de minutos para quitarle pasajeros al que lo sigue. 
Por las particularidades de los sistemas de transporte urbano, que discutiremos a su debido tiempo, estas dificultades no se resuelven mediante la liberalización de tarifas o la competencia entre operadores. Por el contrario, parte de los problemas actuales se generaron o exacerbaron durante la liberalización de los años ochenta. Por razones que detallamos en este trabajo, la competencia por tarifas no funciona. Además, la experiencia internacional indica que la coordinación necesaria para lograr un sistema integrado y eficiente de transporte es difícil de lograr, a menos que la regulación la imponga con incentivos y diseño adecuados.

En resumen: un sistema de transporte eficiente requiere una regulación moderna, que vaya más allá de las licitaciones de los años 90, que, según argumentaremos, hoy parecen agotadas. No se trata de abandonar las licitaciones, sino de mejorarlas introduciendo más competencia, induciendo a que se constituyan empresas especializadas, cambiando el método de cobro y creando una red de recorridos más eficiente. En este trabajo detallamos algunos componentes que deberían formar parte de una reforma radical. El Plan Transantiago comprometido por el gobierno, y que entrará en vigencia en 2005, parece apuntar en la dirección correcta ${ }^{7}$.

\section{MICROS EN SANTIAGO}

\subsection{Una breve historia reciente del transporte público de Santiago}

La historia reciente del transporte público de Santiago se puede dividir en tres períodos ${ }^{8}$. Durante el primero, que terminó en 1979, el Estado intervino activamente como productor (a través de la Empresa de Transportes Colectivos) y regulador de tarifas, rutas y permisos de operación de los transportistas privados. Durante esta etapa, la escasez de oferta fue crónica y la calidad de servicio era baja. Los costos sociales del sistema quedan elocuentemente ilustrados por las imágenes — para quienes tengan la edad de recordar - de buses atestados con pasajeros que viajaban colgados en la pisadera, y de las aglomeraciones en los paraderos a la espera de buses que no pasaban con frecuencia necesaria.

A partir de 1979 comenzó la segunda etapa: se liberalizó la entrada, la determinación de rutas y frecuencias y, en 1983, la tarifas. La reforma descansaba en la premisa de que la oferta de servicios y la calidad serían eficientes, y que la competencia obligaría a los operadores a cobrar una

\footnotetext{
${ }^{7}$ Véase la información disponible en el sitio web del plan: www.transantiago.cl

${ }^{8}$ Cruz (2002) y Dourthé et al. (2000).
} 
tarifa competitiva. La liberalización logró aumentar la oferta. El Gráfico $\mathrm{N}^{\circ} 1$ muestra que entre 1979 y 1983 el número de buses aumentó 40\%, desde 5.185 a 7.278. Luego de la liberalización de tarifas, el número de buses siguió aumentando hasta alcanzar 10.900 en 1988. En 1988 se eliminó el requisito de una autorización del Ministerio de Transportes para ingresar un vehículo u operar un nuevo recorrido. El número de buses siguió creciendo hasta alcanzar su nivel máximo de 13.698 en 1990.

GRÁFICO N ${ }^{\circ}$ : $\quad$ TARIFAS Y NÚMERO DE BUSES, 1979-2001

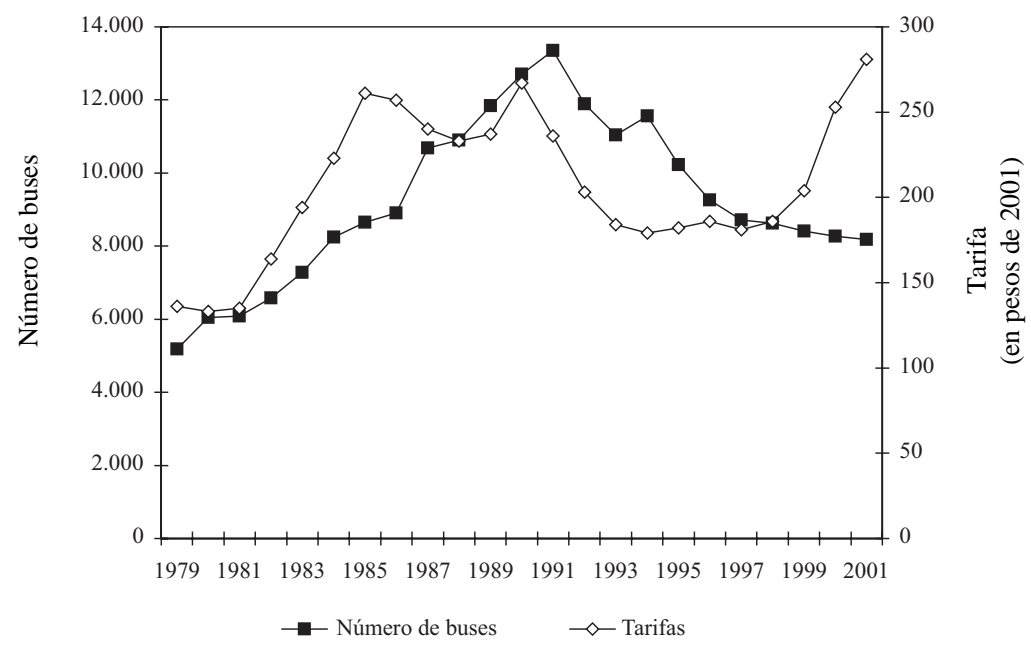

El aumento del número de buses durante los años ochenta benefició a los usuarios porque aumentó la cobertura y disminuyeron los tiempos de espera. Pero también generó problemas crecientes de congestión y contaminación y los precios aumentaron.

El Gráfico $\mathrm{N}^{\circ} 1$ muestra que la liberalización, contrariando las expectativas de quienes la impulsaron, no logró contener los aumentos de precios. A pesar de la creciente oferta de servicios y de la baja sostenida de la capacidad media utilizada por bus — según Cruz (2002), entre 1978 y 1988 la ocupación promedio de un autobús cayó 55\% y la de un taxibús $32 \%$ - las tarifas reales casi se duplicaron entre 1979 y 1990 . Este aumento tarifario nada tuvo que ver con alzas del precio de los combustibles. El Gráfico $\mathrm{N}^{\circ} 2$ muestra que, salvo en 1985, el precio del petróleo crudo en el 
GRÁFICO No ${ }^{\circ}: \quad$ TARIFAS Y PRECIO DEL CRUDO (1979=100)

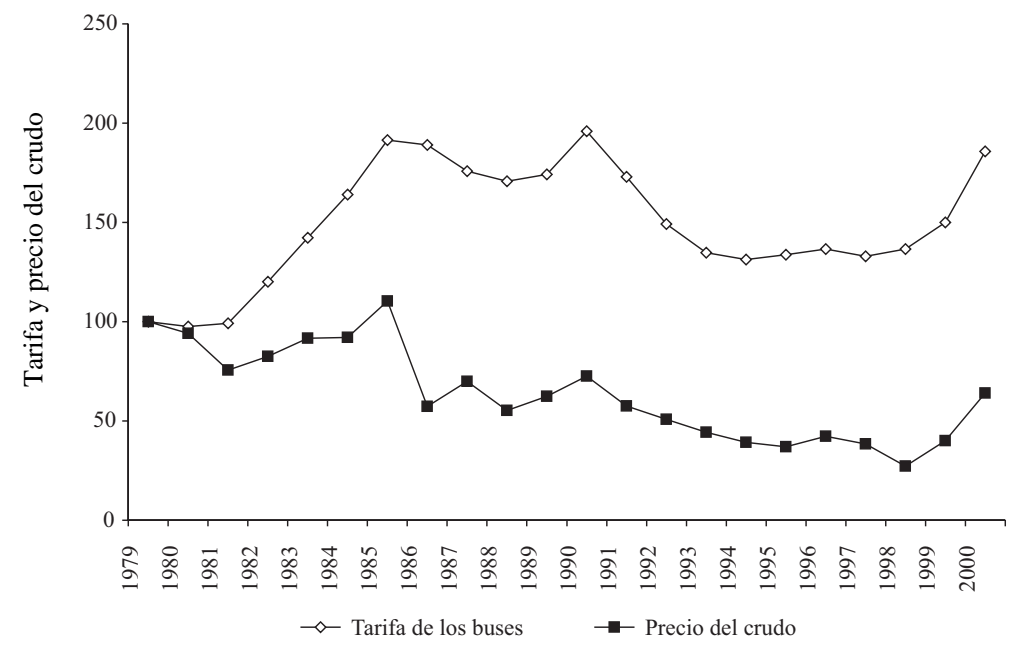

mercado internacional (expresado en moneda doméstica) fue menor que el de 1979 en cada año hasta $2000^{9}$.

¿Qué ocurrió? La evolución de las tarifas durante este período indica una de dos cosas: que no hubo en la práctica competencia real en la industria, a pesar de la liberalización formal (por ejemplo, porque los microbuseros se pusieron de acuerdo para subir las tarifas), o que la competencia no funcionó. Más adelante veremos que probablemente se trató de lo segundo.

Sea como fuere, hacia el final de la década de los ochenta, las altas tarifas y edad promedio de los buses, la clara ineficiencia de la baja ocupación media, sumadas a los costos crecientes de congestión y contaminación, terminaron por sepultar la experiencia liberalizadora. A partir de 1990 comenzó la tercera etapa de la historia regulatoria del sector, caracterizada por más intervención.

En 1991 el gobierno pagó 14 millones de dólares por retirar 2.600 buses. Se estableció además un límite de 18 años para la edad de los buses, lo que implicó renovar cerca de 2.000 buses durante los años siguientes. También se introdujeron normas de emisión para los buses, y se regularon sus características (v. gr., tamaño, espacio entre asientos, chasis, carroce-

${ }^{9}$ Debido a la apertura comercial y a la liberalización del mercado de los combustibles, el precio internacional del crudo es un buen indicador del precio doméstico de los derivados del petróleo. 
ría). La mayoría de las exigencias, incluyendo el límite de la edad de los buses, se fueron haciendo más estrictas con el paso de los años.

La política emblemática de la tercera etapa fue la concesión de recorridos asignados en una licitación. Los contratos de concesión fijan el recorrido, la frecuencia mínima de cada servicio que pasa por la zona regulada (zona que no cubre todo Santiago), la edad máxima de los vehículos (hoy, 10 ó 12 años, según la tecnología), su capacidad (se eliminaron los taxibuses pequeños, las tradicionales "liebres"), y una fórmula para reajustar las tarifas que sigue la variación del precio de los principales insumos ${ }^{10}$. El mecanismo ha sido distinto en cada una de las tres licitaciones realizadas a la fecha (en 1991, 1994 y 1998), aunque en todas se eligió al ganador mediante un sistema de puntajes que combina la tarifa licitada, la edad de la flota y otras variables ${ }^{11}$.

Hasta 1998 las licitaciones lograron frenar y revertir el alza de tarifas de los años ochenta. Como se desprende de los Gráficos $\mathrm{N}^{\circ} 1$ y $\mathrm{N}^{\circ}$ 2, las tarifas reales disminuyeron cerca de 30\% desde 1991 hasta 1993, y se mantuvieron en esos niveles hasta 1998. Esto se debió a la competencia entre operadores en las primeras dos licitaciones y a la introducción de una fórmula para reajustarlas según cambiara el costo de los insumos. La licitación de 1998 no fue tan exitosa. Como veremos más adelante, se han acumulado indicios de que los operadores se coludieron.

Las licitaciones, junto con otras medidas aplicadas durante los años noventa, permitieron reducir el número de micros y aumentar progresivamente la ocupación promedio. El Gráfico $\mathrm{N}^{\circ} 1$ muestra que el número de buses circulando por Santiago disminuyó desde 13.353 en 1991 hasta 8.179 en 2001. Ello se logró fijando el tamaño máximo de la flota en cada recorrido ${ }^{12}$. Durante este período, el número promedio de pasajeros en un día hábil aumentó desde 3.575.942 hasta 4.275.913, con lo cual la cantidad promedio de pasajeros transportados por cada bus en un día hábil casi se duplicó, elevándose de 268 a $523^{13}$.

Formalmente el contrato de concesión fijaba el trazado de cada recorrido y los puntos de origen y destino, pero en la práctica, y salvo un

${ }^{10}$ La fórmula de reajuste es un promedio ponderado del cambio del precio del diésel, el índice de costo de mano de obra, el precio de los neumáticos y el valor de reposición de un bus.

${ }^{11}$ Por ejemplo, en 1992 y 1994 también se incluyó el grado de formalización de los operadores en empresas o asociaciones.

${ }^{12}$ En cada una de las licitaciones la flota máxima se determinó como el producto de la frecuencia de servicios y la longitud del recorrido dividido por 20. Además, en algunos recorridos se aplicó un factor de sobreflota de 4, 5 ó 6 buses.

${ }^{13}$ El número de viajes en un día hábil proviene de las Encuestas de Origen-Destino de 1991 y 2001. 
par de excepciones, en los tres procesos de concesión se han mantenido las rutas que existían a comienzos de los noventa. Esto significa que la cobertura no disminuyó con la licitación. La reforma tampoco redujo la frecuencia de cada recorrido, la cual se establecía en el contrato. Evidencia de lo anterior es que la encuesta de demanda de 1997 mostró que el tiempo promedio de espera de un pasajero no superaba los cuatro minutos en ningún momento del día (Ministerio de Transportes, 1997).

Es decir, la alta cobertura y la frecuencia que los usuarios obtuvieron con la liberalización de los ochenta no se perdió con las concesiones licitadas. La mejor calidad de los vehículos también benefició a los usuarios. Y las normas de emisión más estrictas redujeron la contaminación, hasta el punto de que más de la mitad de los buses que circulan hoy cumplen con las normas de emisión EPA-91 y EPA-94 (Cruz, 2002).

\subsection{Las micros hoy}

A fines de 2001 existían 316 recorridos licitados en la Región Metropolitana. La definición precisa de un servicio licitado es que en algún momento entra a la zona regulada, cuyo límite es el anillo de Américo Vespucio $^{14}$. De los 316 recorridos licitados, 289 son los buses amarillos característicos de Santiago. El resto de los servicios licitados se componía de 21 recorridos de metrobús (que le permite a los pasajeros usar metro y bus pagando una tarifa combinada que es más baja que la suma separada de las dos), tres recorridos expresos y tres metrobuses rurales ${ }^{15}$.

Son 119 los titulares de las concesiones de los 289 recorridos licitados. El titular de una concesión puede ser una asociación de propietarios de buses, un sindicato de trabajadores, una asociaciones gremial o una empresa. Es importante señalar que el titular de una concesión no necesariamente es propietario de los buses y puede gestionar un recorrido vendiendo cupos a otros propietarios. De hecho la cifra de 119 titulares esconde la gran atomización de la propiedad de los buses en Santiago: en promedio, cada empresario tiene sólo 2,11 micros $^{16}$. El Cuadro $\mathrm{N}^{\circ} 1$ presenta la información del número de buses por propietario a diciembre de 2001. La columna 4 muestra que el $69,1 \%$ de los buses en circulación pertenecen a un dueño

${ }^{14}$ Fuera de la zona regulada pueden operar servicios no licitados, siempre y cuando todo su recorrido se haga fuera de la zona regulada. A fines de 2001 había 180 servicios no licitados autorizados.

${ }^{15}$ La fuente es el Ministerio de Obras Públicas, Transporte y Telecomunicaciones.

${ }^{16}$ Esta cifra incluye buses de recorridos licitados, expresos y metrobuses. La cifra de micros por empresario en los recorridos licitados es casi igual: 2,13. 
CUADRO $N^{\circ}$ 1: $\quad$ NÚMERO DE BUSES POR EMPRESARIO EN LA REGIÓN METROPOLITANA (A DICIEMBRE DE 2001)

\begin{tabular}{lcccc}
\hline Número de buses & $\begin{array}{c}(1) \\
\text { Número de } \\
\text { por propietario } \\
\text { en la categoría }\end{array}$ & $\begin{array}{c}(2) \\
\text { Número total } \\
\text { de buses en } \\
\text { la categoría }\end{array}$ & $\begin{array}{c}(3) \\
\text { Porcentaje del } \\
\text { total de buses } \\
\text { en la categoría }\end{array}$ & $\begin{array}{c}(4) \\
\text { Porcentaje } \\
\text { acumulado }\end{array}$ \\
\hline & 2.463 & 2.463 & 30,2 & 30,2 \\
1 & 774 & 1.548 & 19,0 & 49,2 \\
2 & 293 & 879 & 10,8 & 60,0 \\
3 & 117 & 468 & 5,7 & 65,7 \\
5 & 56 & 280 & 3,4 & 69,1 \\
Entre 6 y 10 & 106 & 786 & 9,6 & 78,7 \\
Entre 11 y 20 & 33 & 479 & 5,9 & 84,6 \\
Entre 21 y 50 & 21 & 616 & 7,6 & 92,2 \\
Más de 50 & 5 & 629 & 7,8 & 100 \\
Total & 3.868 & 8.148 & 100 & \\
\hline
\end{tabular}

Fuente: Ministerio de Obras Públicas, Transportes y Telecomunicaciones.

Nota: Incluye buses de recorridos licitados, metrobuses y expresos.

que tiene cinco o menos buses ${ }^{17}$. En muchos casos el titular de la concesión es una asociación de propietarios que se formó para licitar un recorrido pero que no cuenta con una administración central que opere el negocio, y por ende no es ni se comporta como una empresa.

Según EMG Consultores (2002), la longitud promedio de un recorrido es $28 \mathrm{~km}$ de Norte a Sur y $35 \mathrm{~km}$ de Poniente a Oriente; vale decir, en promedio cada recorrido cruza Santiago casi por completo en una u otra dirección ${ }^{18}$. Según Malbrán (2001), el 80\% de los recorridos pasa por seis ejes centrales: Gran Avenida-Independencia, Recoleta-Santa Rosa, y Vicuña Mackenna de Norte a Sur; y San Pablo, Pajaritos-Alameda-Apoquindo e Irarrázaval de Poniente a Oriente. Como se dijo, según la Encuesta de Origen y Destino de 2001, cada día laboral se realizan 4.275.913 viajes en bus. De éstos, el 19,1\% son desplazamientos escolares.

Los contratos de concesión fijan el recorrido, las frecuencias mínimas y el número mínimo y máximo de buses que pueden operar en un

${ }^{17}$ Sin embargo, esta estructura de propiedad esconde que, por razones de responsabilidad legal frente a accidentes $\mathrm{u}$ otras demandas judiciales (un propietario es responsable legalmente hasta un monto equivalente al capital invertido), muchos buses están formalmente inscritos a nombre de familiares cercanos del verdadero propietario.

${ }^{18}$ El Gran Santiago cubre alrededor de 60.000 ha. El diámetro de un círculo de tal superficie es $27,6 \mathrm{~km}$. 
recorrido. Para cambiar el trazado de un recorrido, una empresa debe pedir autorización al Secretario Regional Ministerial de Transportes y Telecomunicaciones (el así llamado Seremi). En general, el concesionario administra las frecuencias de un recorrido mediante una orden de despacho de buses, y a cada bus le fija un tiempo máximo para que complete su recorrido. Si el chofer no cumple se le cobra una multa.

Las empresas de transporte se agrupan en seis asociaciones gremiales, y varias se coordinan para negociar con las autoridades reguladoras. Cuatro de las seis asociaciones están agrupadas en el Consejo Superior del Transporte $(\mathrm{CST})^{19}$. Hasta poco tiempo atrás este Consejo incluía también a los vehículos de la Federación Siglo XXI, pero ésta se marginó debido a un conflicto suscitado en las elecciones del CST.

\subsection{Los problemas}

A pesar del relativo éxito de la licitación de recorridos, existe abundante evidencia de que el sistema aún no opera eficientemente.

El primer problema es la duplicación de recorridos en el centro. Si bien el Ministerio de Transportes puede dictar los recorridos de cada servicio en el contrato de concesión, en la práctica tomó los recorridos existentes a comienzos de los noventa, sin mejorar la red. En parte esto obedece a la dificultad técnica de diseñar una trama optimizada de recorridos, y al hecho de que su aplicación hubiera requerido transbordos e integración tarifaria ${ }^{20}$. A comienzos de los noventa las autoridades del sector estaban preocupadas de afianzar la licitación (que fue resistida por el gremio del sector mediante paros y boicots a las licitaciones) y no de reorganizar la red de recorridos. Como se argumentará más adelante, esta superposición de recorridos no sólo congestiona la ciudad, sino que además es ineficiente y encarece la operación del sistema.

${ }^{19}$ Se trata de la Asociación Gremial Metropolitana de Transporte de Pasajeros (AGMTP), que agrupa a cerca de 3.500 buses; la Federación Gremial de Dueños de Buses y Taxibuses, que reúne a cerca de 400 buses de pequeños propietarios; la Federación Nacional de Buses y Taxibuses (FNTCH), que agrupa a unos 600 buses; la Asociación de Metrobuses (AM), que agrupa a 500 buses de este tipo de recorridos; la Federación Siglo XXI (FS21), que reúne a 1.000 buses; y la Asociación de Empresarios del Transporte de Pasajeros (AETP), que agrupa a cerca de 800 buses (EMG Consultores, 2002).

${ }^{20}$ La integración tarifaria es un sistema de cobro que le permite a cada pasajero cambiarse de una línea a otra sin pagar de nuevo. El metro funciona con un sistema integrado, ya que pagando un pasaje se puede utilizar cualquier línea de metro. Los servicios de metrobús, en los que un pasajero que usa este servicio en conjunto con el metro paga menos que el costo de los dos pasajes por separado, son un intento por introducir la integración tarifaria en el sistema de transporte público en Santiago. 
El segundo problema es la calidad deficiente de los buses. Si bien su edad promedio ha disminuido desde que comenzó el sistema de licitación en 1990, se puede apreciar en el Gráfico $\mathrm{N}^{\circ} 3$ que más de la mitad tiene ocho o más años. Aparte de la incomodidad que soportan los pasajeros, la antigüedad y calidad de los buses afecta directamente a la contaminación atmosférica y acústica.

\section{GRÁFICO Nº 3: $\quad$ AÑO DE FABRICACIÓN DE LOS BUSES QUE CIRCULABAN EN 2002}

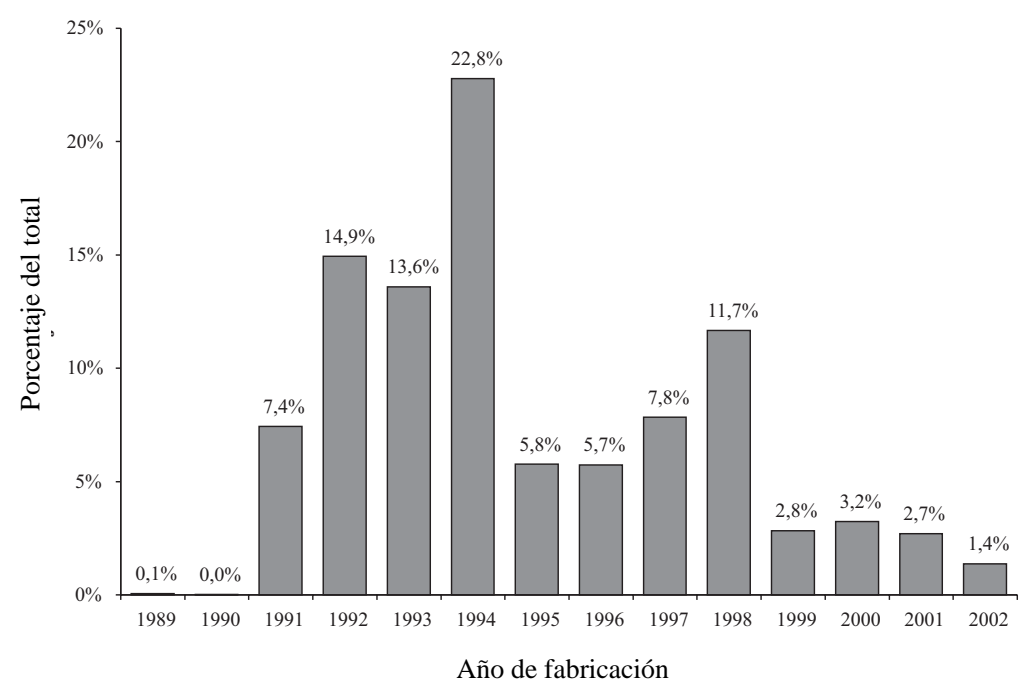

El tercer problema es que el tránsito es muy inseguro. El año 2000 ocurrieron 4.943 accidentes en la zona urbana de la Región Metropolitana en los que estuvieron envueltos vehículos de la locomoción colectiva; en ellos se lesionaron 4.668 personas y 116 murieron. El año 2001 la cantidad de accidentes aumentó a 7.392 y los lesionados a 5.699, con 112 muertos ${ }^{21}$. Estos números implican que los buses participan entre 13 y 20 accidentes diarios y que cada tres días muere una persona a raíz de ellos. Aunque no es fácil obtener datos internacionales, estas cifras parecen altas. Por ejemplo: dado que hay cerca de 8.000 buses en Santiago, en promedio cada uno está involucrado en un accidente al año.

Cuarto, la estructura empresarial del sector es informal y atomizada. No se trata solamente de que el empresario promedio tenga pocos buses. El

${ }^{21}$ La fuente es la Comisión Nacional de Seguridad de Tránsito en base a cifras de Carabineros de Chile. 
problema es que las pequeñas empresas no tienen acceso a crédito ni a tecnologías más avanzadas de administración, cobro y transporte. Ello impide el desarrollo de un sistema de transportes de superficie más eficiente.

Por último, si bien la licitación ayudó a disminuir las tarifas, en la siguiente sección mostramos que éstas siguen siendo altas para algunos recorridos. Además, su estructura es inadecuada. Todos los recorridos cobran la misma tarifa, independientemente de su longitud, los costos y la demanda que enfrentan. Tarifas mayores que las necesarias generan varios problemas. Como los viajes cuestan más de lo necesario, se desincentiva sin razón el uso del transporte público. Además, tarifas injustificadamente altas son la fuente de varios problemas que exacerban los ya existentes en el sector. Finalmente, si se considera que el único medio de transporte de los usuarios más pobres son los buses, la situación actual es socialmente injusta ${ }^{22}$.

En años recientes, el modelo regulatorio aplicado desde 1991 se ha ido agotando. Entre 1998 y 2002 el gremio logró rearticularse y presionar exitosamente para obtener ciertas concesiones de las autoridades. Por ejemplo, cuando amenazó con un paro el 2000, el ministro del ramo flexibilizó el requisito de que los buses funcionen con una caja de cambio automática. Más grave aún, es muy probable que los microbuseros se hayan coludido en la licitación de recorridos de 1998. En esa ocasión hubo sólo un licitante por recorrido en el $76 \%$ de las líneas y el $97 \%$ ofreció la tarifa máxima permitida en las bases ${ }^{23}$. Todo ello sugiere que es conveniente modificar la regulación y las licitaciones.

\section{LAS RENTAS DEL TRANSPORTE PÚBLICO ${ }^{24}$}

Uno de los hechos más notorios del actual sistema de transporte público es que muchos buses circulan casi vacíos. La ocupación promedio aumentó durante la última década, pero sigue siendo casi un tercio menor que la de ciudades similares como Bogotá. Desde el punto de vista social ello parece ineficiente, porque la contaminación y la congestión producida por cada pasajero trasladado crecen en la medida en que cae la ocupación promedio de cada bus.

${ }^{22}$ Según la Quinta Encuesta de Presupuestos Familiares (tomada entre agosto de 1996 y julio de 1997) del INE (Instituto Nacional de Estadísticas), el 20\% de los hogares más pobres del Gran Santiago gastaba el 7\% de su presupuesto mensual en transporte público. Por lo tanto, el transporte público es un gasto relevante para las familias pobres.

${ }^{23}$ Véase a Sanhueza y Castro (1999).

${ }^{24}$ Una renta es la remuneración que recibe un factor productivo (v. gr., un bus) por sobre su costo de oportunidad. 
¿Qué podría explicar este exceso de oferta? Para un economista resulta natural pensar que el precio de los pasajes es muy superior a los costos. Si así fuera, las inversiones obtendrían un retorno mayor que en otras industrias de riesgo similar, y muchos querrían entrar en el negocio. En otras palabras, el exceso de oferta puede deberse a que las tarifas son demasiado altas. A continuación mostraremos evidencia de que las tarifas son muy altas, y luego explicaremos por qué.

\subsection{Las tarifas y la rentabilidad del sector}

¿Son caros los pasajes de micro en Santiago? El Cuadro $N^{\circ} 2$ muestra el cálculo de la rentabilidad que se obtiene invirtiendo en un bus, de acuerdo con información de un estudio pormenorizado de los costos de las empresas de transporte hecho por EMG Consultores (2002) (los detalles del cálculo se explican en el Recuadro, más adelante). Clasificamos a los recorridos según la cantidad de pasajeros por viaje, la así llamada densidad de la demanda. Las rutas de alta densidad son en promedio más cortas, con 55 kilómetros por viaje, en comparación con 63 kilómetros por viaje para las de densidad media, y 70 kilómetros por viaje para las de densidad baja. Por ello, los costos de operación son más altos en las rutas de densidad media y baja. Al existir una sola tarifa para todos los recorridos, esta diferencia en demanda y costos implica que los recorridos densos ganan más.

La última fila del Cuadro $\mathrm{N}^{\circ} 2$ dice que un bus que sirve una ruta de alta densidad obtiene una rentabilidad de 26,8\%. La inversión renta 13,6\% si el recorrido es de densidad media y sólo $3 \%$ si es de densidad baja. La rentabilidad promedio de la industria es de $14,6 \%$.

¿Son estas rentabilidades excesivamente altas? La respuesta depende del riesgo no diversificable que enfrenten los inversionistas en esta industria $^{25}$. Pero, en cualquier caso, parece prudente sostener que en las rutas de alta densidad, que son casi un tercio de los recorridos, se obtienen rentas económicas. También parece razonable afirmar que invertir en rutas de baja densidad no es un negocio muy rentable. Es decir, las tarifas parecen altas para a lo menos un tercio de los buses y quizás hasta dos tercios.

Un dato que confirma esta hipótesis es el siguiente: en 123 de los 280 recorridos el número de buses es igual al máximo permitido por contrato de concesión ${ }^{26}$. Invertir en buses hasta el tope permitido por el contra-

${ }^{25} \mathrm{El}$ riesgo no diversificable es aquel cuyos efectos no se pueden eliminar invirtiendo en otras industrias.

${ }^{26}$ Los datos son de la Subsecretaría de Transportes. 


\section{CUADRO N ${ }^{\circ} 2: \quad$ LA RENTABILIDAD DE INVERTIR EN UN BUS SEGÚN LA DENSIDAD DE LA RUTA}

\begin{tabular}{|c|c|c|c|c|}
\hline & $\begin{array}{c}\text { (1) } \\
\text { Ruta de alta } \\
\text { densidad }\end{array}$ & $\begin{array}{c}\text { (2) } \\
\text { Ruta de } \\
\text { densidad media }\end{array}$ & $\begin{array}{c}\text { (3) } \\
\text { Ruta de } \\
\text { baja densidad }\end{array}$ & $\begin{array}{c}\text { (4) } \\
\text { Promedio }\end{array}$ \\
\hline Porcentaje de todos los recorridos & $32 \%$ & $33 \%$ & $34 \%$ & \\
\hline \multicolumn{5}{|l|}{ Ingresos } \\
\hline Tarifa normal $(\$)$ & 290 & 290 & 290 & \\
\hline Tarifa escolar $(\$)$ & 100 & 100 & 100 & \\
\hline Porcentaje de viajes escolares & $19,1 \%$ & $19,1 \%$ & $19,1 \%$ & \\
\hline Tarifa promedio por pasajero $(\$)$ & 262 & 262 & 262 & \\
\hline Viajes/día (punta) & 2,5 & 2,5 & 2,5 & \\
\hline Viajes/día (fuera de la punta) & 3,5 & 3,5 & 3,5 & \\
\hline Kilómetros por viaje & 55,2 & 63,3 & 70,3 & \\
\hline Pasajeros/km (punta) & 1,77 & 1,38 & 1,11 & \\
\hline Pasajeros/km (fuera de la punta) & 1,48 & 1,11 & 0,92 & \\
\hline Días en circulación por mes & 26 & 26 & 26 & \\
\hline Pasajeros por día & 530,1 & 463,0 & 421,5 & \\
\hline Ingresos por día & 138.943 & 121.348 & 110.467 & \\
\hline Total de ingresos mensuales & 3.612 .511 & 3.155 .041 & 2.872 .153 & \\
\hline \multicolumn{5}{|l|}{ Gastos } \\
\hline Combustible & 784.911 & 900.088 & 999.624 & \\
\hline Remuneraciones $^{1}$ & 722.502 & 631.008 & 574.431 & \\
\hline Lubricantes & 41.454 & 46.593 & 51.746 & \\
\hline Neumáticos & 192.640 & 220.908 & 245.336 & \\
\hline Seguros & 100.000 & 100.000 & 100.000 & \\
\hline Pago de planilla del terminal & 200.000 & 200.000 & 200.000 & \\
\hline Gastos de mantención y reparación & 152.171 & 152.171 & 152.171 & \\
\hline Otros $^{2}$ & 78.829 & 75.338 & 73.179 & \\
\hline Impuestos & 71.713 & 71.713 & 71.713 & \\
\hline Total de gastos mensuales & 2.344 .220 & 2.397 .819 & 2.468 .199 & \\
\hline Ingreso neto mensual & 1.268 .292 & 757.223 & 403.954 & 793.081 \\
\hline Ingreso neto diario & 48.780 & 29.124 & 15.537 & 30.503 \\
\hline Valor bus ${ }^{3}$ & 53.784 .400 & 53.784 .400 & 53.784 .400 & 53.784 .400 \\
\hline Vida útil (años) & 12 & 12 & 12 & 12 \\
\hline Valor residual & 8.067 .660 & 8.067 .660 & 8.067 .660 & 8.067 .660 \\
\hline Tasa interna de retorno & $26,8 \%$ & $13,6 \%$ & $3,0 \%$ & $14,6 \%$ \\
\hline
\end{tabular}

Notas: (1) Remuneración de 1,5 choferes por bus.

(2) Incluye permiso de circulación, revisión técnica, cotización salud y previsión, aporte patronal y gastos en boletos. (3) Un bus moderno (post 1994) incluye pago de IVA y los aranceles de importación. Se supuso que el tipo de cambio era igual a \$ 650 por dólar.

Fuente: Elaboración propia con datos de EMG Consultores (2002). Para mayores detalles véase el Recuadro $\mathrm{N}^{\circ} 1$. 
RECUADRO: ESTIMANDO LAS RENTAS DEL TRANSPORTE PÚBLICO DE SANTIAGO

La mayor parte de la información con que estimamos la rentabilidad por bus proviene de EMG Consultores (2002), aunque modificamos algunos supuestos. El estudio de EMG Consultores (2002) se basa en antecedentes de otras investigaciones y documentos, incluyendo libros contables y entrevistas con operadores de varios recorridos. Dicho estudio estimó los costos para dos tipos de buses: los de tecnología tradicional y más contaminante, y los que ingresaron a partir 1994 y que cumplen con la norma de emisión EPA 91. La información que utilizamos en este trabajo es la de este tipo de bus más moderno.

Los datos del estudio de EMG Consultores (2002) fueron recopilados a fines de 2001 y comienzos de 2002, cuando el valor del pasaje era de \$ 290 para adultos y \$ 100 para escolares ${ }^{1}$. La Encuesta de Origen-Destino del 2001 muestra que el 19\% de los viajes durante un día laboral corresponden a traslados de escolares. Suponiendo que 20 de los 26 días que en promedio opera un bus son laborales, y que no hay pasajeros escolares los días festivos, las cifras anteriores implican que el valor del pasaje promedio por pasajero durante ese período fue de $\$ 262$.

EMG Consultores (2002) clasificó los recorridos en tres tipos: de alta, de media y de baja densidad. Los de alta densidad son aquellos que transportan a más de 1,65 pasajeros por kilómetro durante el período de punta. Los de densidad media transportan entre 1,35 y 1,65 pasajeros por kilómetro, y los de baja densidad, menos de 1,35 pasajeros por kilómetro. En promedio, el largo de cada recorrido es de $55 \mathrm{~km}$ para los de alta densidad; $63 \mathrm{~km}$ para los de densidad media; y 70 kilómetros para recorridos de baja densidad. Un "recorrido" es una vuelta completa de ida y vuelta al terminal de partida.

En promedio, un bus hace seis viajes por día. Sin embargo, un bus realiza más recorridos en horario fuera de punta que en horario punta, por dos motivos. Primero, por que en días festivos la demanda es siempre menor a la del día laboral (menos del 50\%), por lo que al menos un día y medio en la semana (sábado por la tarde y domingo) todos los viajes de un bus son en horario fuera de punta. Por otro lado, la congestión es mayor en el horario punta, de manera que los recorridos son más lentos y no se pueden completar muchas 
vueltas. En EMG Consultores (2002) se supone que, en promedio, 2,5 de los seis viajes se hacen durante el período de punta y el resto fuera de la punta ${ }^{2}$. Utilizando datos de pasajeros por kilómetro promedio por tipo de recorrido y horario, es posible estimar el número de pasajeros promedio que transporta un bus diariamente. El Cuadro $\mathrm{N}^{\circ} 2$ muestra el resultado de estos supuestos. En los recorridos de alta densidad, un bus transporta, en promedio, 530 pasajeros diarios, mientras que las cifras para un bus en recorrido de densidad media es de 463 y para un recorrido de densidad baja, de 421 . Utilizando los datos de pasajeros diarios y la tarifa promedio calculada anteriormente, obtuvimos el ingreso mensual de cada tipo de recorrido.

¿Son razonables estas estimaciones de pasajeros diarios? Para contestar esta pregunta, contrastamos nuestras estimaciones de número de viajes diarios con la información de la Encuesta de OrigenDestino de 2001. Dicha encuesta estima que el número de viajes en bus en un día laboral asciende a 4,3 millones de pasajeros. Si se supone que 20 de los 26 días que opera un bus al mes son laborales y que la demanda por viajes disminuye un $50 \%$ durante los días festivos, el número de viajes promedio es de 3,8 millones de pasajeros por día. Considerando que de los 8.179 buses que operaron en Santiago en 2001, 32\% lo hacían en rutas de alta densidad, 33\% en rutas de densidad media y $34 \%$ en rutas de baja densidad, concluimos que los supuestos del Cuadro $\mathrm{N}^{\circ} 2$ implican un promedio de 3,8 millones de pasajeros por día, cifra muy similar a la que se deduce de la Encuesta de Origen-Destino de 2001.

En referencia a los costos, hay varios gastos fijos, tales como seguros (\$100.000 mensuales), permiso de circulación (\$28.410 al año), revisión técnica (\$28.410 al año), pago de planilla en el terminal (\$ 200.000 al mes), gastos de mantención y reparación (\$1.826.050 al año), cotizaciones en AFP, salud y aporte patronal (\$ 46,526 en total al mes). EMG Consultores (2002) también considera un gasto fijo de $\$ 30.000$ al mes para uniformes de los choferes. Consideramos exagerada esta cifra y no la incluimos en el cálculo, ya que muchos choferes trabajan sin uniforme.

Los gastos variables más importantes son el pago a los choferes y el combustible. Supusimos que la remuneración neta de los choferes, incluyendo bonos, es igual al 20\% de los ingresos. En general, durante un mes cada bus es operado por más de un chofer, por lo que las cifras que presentamos en el Cuadro $\mathrm{N}^{\circ} 2$ no deberían inter- 
pretarse como el sueldo de una persona. Si suponemos que 1,5 choferes manejan cada micro mensualmente, las cifras de remuneración equivalen a un sueldo líquido mensual de entre $\$ 380.000$ y $\$ 480.000$, dependiendo del tipo de recorrido. Estas cifras pueden parecer altas para un trabajo que no requiere mucha preparación. Sin embargo son coherentes con (e incluso un poco menores) la información obtenida por diferentes medios, incluyendo entrevistas directas con operadores. Estas cifras pueden indicar que parte de las rentas se disipan en salarios que están sobre los del mercado para los choferes.

Para el combustible consideramos un rendimiento de 2,5 kilómetros por litro, cifra obtenida de EMG Consultores (2001). Además, el precio del diésel, incluyendo impuestos, fue de $\$ 228$ por litro en el período en que se realizó dicho estudio. Los restantes gastos operativos importantes son los de neumáticos, donde se supuso que se requieren siete neumáticos nuevos cada 60 mil kilómetros y siete neumáticos recauchados cada 40 mil kilómetros. Los precios considerados fueron de $\$ 147,500$ para un neumático nuevo y $\$ 59.000$ para uno recauchado. El resto de los gastos operativos incluye lubricantes e impuestos.

Con la información anterior es posible calcular el flujo de caja neto que genera un bus. Los flujos mensuales por tipo de recorrido van desde $\$ 400.000$, si se trata de un recorrido de baja densidad, hasta $\$ 1.360 .000$ para recorridos de alta densidad. En términos diarios estas cifras equivalen a $\$ 15.500$ y $\$ 49.000$ pesos por día. EMG Consultores (2002) estimó el precio de un bus en $\$ 53.784 .000$, lo que equivale a 85.000 dólares al tipo de cambio promedio de 2001, que fue de $\$ 635$ por dólar. Se supuso una vida útil de 12 años para los buses y un valor residual de $\$ 8.067 .660$.

Con las cifras y supuestos anteriores, la tasa de rentabilidad de la inversión en un bus asciende a $26,8 \%$ en un recorrido de alta densidad, $13,6 \%$ en un recorrido de densidad media, y $3,0 \%$ en un recorrido de baja densidad. El promedio de rentabilidad de la industria es $14,6 \%$.

\footnotetext{
${ }^{1}$ Para mantener la consistencia de la información, en el presente trabajo no se actualizaron los datos de precios.

${ }^{2}$ Esto es coherente con un viaje en el horario punta de la mañana de lunes a sábado y dos viajes en el horario punta de mediodía o de la tarde los días lunes a viernes. Como un bus trabaja en promedio 26 días al mes, esto equivale a que 64 de los 156 viajes mensuales se hacen en el período punta, o sea 2,46 de los 6 viajes diarios.
} 
to puede ser indicio de rentas económicas. De ser así, las cifras anteriores indicarían que el $46 \%$ de las rutas obtiene ganancias excesivas. Tarifas mayores que las necesarias para cubrir los costos de capital y operación de las micros generan varios problemas. Uno de ellos es que hay fuertes estímulos para incrementar las frecuencias y pelearse por los lucrativos pasajeros adicionales. Ello explicaría el exceso de buses en las calles de Santiago, la baja capacidad utilizada y la guerra entre choferes por captar pasajeros.

Sea cual fuere el nivel exacto de la rentabilidad de cada recorrido, es indiscutible que la tarifa uniforme distorsiona el crecimiento de la ciudad y la demanda por viajes porque estimula los viajes que se originan o tienen como destino puntos lejanos de la ciudad. Por ende, contribuye a la expansión excesiva de Santiago.

Para proseguir es importante contestar tres preguntas. Primero, ¿por qué son altas las tarifas si existe un mecanismo de licitación competitivo para asignar los contratos de concesión? Segundo, ¿quién se queda con las rentas? Esta pregunta es importante, ya que permite identificar quiénes se opondrán a una reforma que amenace esas rentas. Y tercero, ¿será suficiente generar competencia y así reducir las tarifas para mejorar el sistema de transportes en Santiago? Contestamos cada una a continuación.

\section{2. ¿Por qué se mantienen altas las tarifas de algunos recorridos?}

A pesar de que las licitaciones redujeron las tarifas, éstas aún son excesivas en muchos recorridos. Los contratos de concesión fijan la tarifa máxima, pero los operadores pueden cobrar menos si así lo desean. ¿Por qué la competencia no ha reducido las tarifas en los recorridos más rentables?

Para entender lo que ocurrió durante los noventa, hay que comenzar por analizar la experiencia de los ochenta. Muchos analistas han explicado el alza de tarifas por la colusión que habría sido impuesta por las asociaciones gremiales ${ }^{27}$. La evidencia que respalda esta hipótesis es abundante: pasajes iguales en todos los recorridos, a pesar de las diferencias de costos, y más de 20 reclamos presentados ante la Comisión Antimonopolio acusando prácticas colusivas ${ }^{28}$. Pero ¿cómo se las arreglaban las asociaciones gremiales para disciplinar a sus miembros y excluir a potenciales competidores independientes ${ }^{29}$ ?

\footnotetext{
${ }^{27}$ Por ejemplo, Cruz (2002), Paredes y Baytelman (1996) y Fernández (1994).

${ }^{28}$ Paredes y Baytelman (1996).

${ }^{29}$ No era obligatorio para un dueño de buses pertenecer a una asociación y había libre entrada a los recorridos.
} 
Existen al menos tres explicaciones complementarias. La primera apunta a que la asociación obtenía seguros más baratos y podía premiar a los miembros que cobraban sus tarifas. Si el operador de un bus bajaba la tarifa, se le castigaba eliminándolo del orden de despacho de los buses (lo que equivalía a expulsarlo de la asociación) y perdía los beneficios del seguro. La segunda explicación es que los miembros de la asociación podían "acosar" a un operador independiente que no respetara el precio mínimo fijado por la asociación. Esto lo podían lograr asegurándose que un bus de la asociación siempre efectuara el recorrido un poco antes que el bus entrante, para quitarle los pasajeros. Por último, según los antecedentes presentados a la Comisión Antimonopolios, tampoco se puede descartar el uso de la agresión o daño a los buses.

Un aspecto interesante de los años ochenta es que el cartel pudo disciplinar a sus miembros para que no bajaran las tarifas, pero no fue capaz de impedir la entrada de nuevas micros ${ }^{30}$. Ello parece haber dado lugar a una dinámica tal que los aumentos de tarifas estimulaban la entrada de más operadores, incentivando a su vez nuevos aumentos del pasaje para compensar la caída de la ocupación promedio ${ }^{31}$. Este aumento simultáneo del pasaje y el número de buses es justamente lo que se observó en Santiago durante los años ochenta.

Como señala Fernández (1994), la liberalización del mercado en Chile durante los ochenta sustituyó la regulación del Estado por un cartel. Es importante enfatizar que lo que ocurrió en Santiago no es particular de Chile. Klein et al. (1997), luego de revisar estudios de Lima, Hong Kong, Estambul, Buenos Aires, Manila, Calcuta, Caracas y varias ciudades en los Estados Unidos, concluyen que cuando existe libre entrada surgen asociaciones que intentan racionalizar las operaciones, estableciendo rutas y horarios, y regulando conflictos que muchas veces son violentos. Naturalmente, estas asociaciones pronto se convierten en carteles que fijan tarifas y limitan la entrada. Es común observar que las asociaciones usan violencia, intimidación y otras estrategias para imponer disciplina, pero su poder también emana de su capacidad para obtener seguros, compartir los gastos de mantenimiento y proteger a los asociados de los conflictos propios de un mercado regulado. Glaister (1998) indica que esta tendencia a "cartelizarse" se ha observado incluso en la industria de coches de caballos en Inglaterra en el siglo XIX. Según él, los carteles surgen porque todos

${ }^{30}$ Según Fernández (1994), las asociaciones vendían el derecho de entrada a un nuevo bus, lo cual es evidencia de que durante esa época había rentas.

${ }^{31}$ Esta dinámica puede ser factible en algunas condiciones, dependiendo de la estructura de costos, la elasticidad de demanda y el rezago con que entran los nuevos operadores si la tarifa aumenta. Véase a Paredes y Baytelman (1996). 
ganan compartiendo activos comunes, coordinando los recorridos y morigerando los conflictos y la violencia entre operadores.

Si durante la década de los ochenta las autoridades fueron incapaces de romper el cartel, durante los noventa esta falla ha sido sólo parcialmente corregida. ¿Por qué no se redujo más la tarifa, a pesar de las licitaciones aparentemente competitivas? En parte se debió a que el mecanismo de licitación contempla un complejo sistema de puntaje, en el cual la tarifa es sólo uno de los componentes. Por ejemplo, en la licitación de 1991 se evaluaron la edad de los buses, su tamaño, el método de cobro de pasajes, las tarifas, y otras dimensiones de la calidad de servicio. Seguramente una licitación con múltiples variables relaja la competencia en tarifas.

Pero, al igual que durante los ochenta, es probable que lo más importante haya sido la competencia insuficiente. De acuerdo con Fernández (1994), en 1991 se recibieron 307 propuestas para 255 rutas, es decir, 1,2 ofertas por ruta. Si bien la tarifa nominal disminuyó de \$ 100 a \$91,5, el bajo número de propuestas por ruta sugiere que el proceso no fue intensamente competitivo. Esto puede haberse debido a una acción concertada de los operadores, o a que pocos se interesaban ${ }^{32}$.

En la licitación de 1998 la ausencia de la competencia fue aún más notoria. Como ya dijimos, hubo sólo un licitante por recorrido en el 76\% de las líneas, y el 97\% de las ofertas eran por la tarifa máxima permitida en las bases (Sanhueza y Castro, 1999). Es decidor que la mayoría de los sobres en que se entregaron las ofertas llegaron juntos al Ministerio. Desde entonces el gremio ha logrado negociar exitosamente un alza de tarifas, una extensión de la edad máxima de los buses de diez a 12 años y la flexibilización de otras normas técnicas.

\section{3. ¿Quién se queda con las rentas?}

¿Cuánto suman las rentas? Para estimarlas hemos supuesto que sólo las obtienen el $32 \%$ de los buses que sirven recorridos de alta densidad. De este modo, estimamos los ingresos que se requieren para obtener una tasa de rentabilidad igual a $13,6 \%$, la misma de un bus que sirve una ruta de densidad media. Los ingresos mensuales requeridos son de sólo \$ 757.283, en vez de los \$1.268.292 que nosotros estimamos en el Cuadro $\mathrm{N}^{\circ} 2$.

${ }^{32}$ No hay que olvidar que el cartel estaba muy activo por estas fechas. La asociación gremial se opuso tenazmente a la licitación: hizo un paro en abril de 1991 y boicoteó la primera licitación en abril de 1991. Sólo se pudo licitar en diciembre de 1991, después que intervino la Comisión Preventiva Antimonopolios y el Ministerio de Transportes dividió al cartel mediante algunas medidas administrativas (tales como prohibir que buses adquiridos antes de 1979 entraran al centro). Para más detalles, véase Fernández (1994). 
Suponiendo 8.000 buses en Santiago, estos montos arrojan $\$ 15.700$ millones, o cerca de 22 millones de dólares al año.

Pero hay más. Dos categorías de gastos del Cuadro $\mathrm{N}^{\circ} 2$ llaman la atención. Primero, el "pago de planilla del terminal". Éste es un pago que debe hacer cada micrero al titular de la concesión a cambio del derecho de operar en el recorrido. Fuera de financiar ciertos gastos de infraestructura (v. gr., las garitas) y de administración del recorrido, la mayor parte es una renta que se lleva el titular que, como señalamos más arriba, puede ser una asociación gremial, una asociación de pequeños propietarios, o una empresa que no tiene buses y sólo gestiona el recorrido. Supongamos que el 75\% de este pago es innecesario, que el $25 \%$ restante se justifica por los gastos de administración del recorrido, y que sólo los buses en los recorridos de densidad media y alta pagan esta cuota ${ }^{33}$. Con estos supuestos, las rentas implícitas que se transfieren a los titulares de las concesiones ascienden a más de $\$ 9.300$ millones, o cerca de 13 millones de dólares al año.

La segunda categoría que llama la atención es la remuneración de los choferes, que parece alta. En el Cuadro $\mathrm{N}^{\circ} 2$ hemos estimado que cada chofer gana entre \$ 380.000 y \$ 480.000 mensuales. Según la encuesta de Empleo y Desempleo de la Universidad de Chile de marzo de 2003, el salario promedio de los choferes en Santiago era $\$ 283.000$. Si su trabajo no requiere capacitación especial ¿por qué un chofer gana mucho más que el sueldo promedio de un trabajador en Santiago? Una explicación posible es que el sistema actual premia la habilidad para competir por pasajeros. Pero, dejando de lado los problemas de tránsito que esta competencia genera, el "premio" es una ineficiencia más del transporte urbano. Es posible imaginar un sistema según el cual los choferes ganen un sueldo fijo, no compitan por pasajeros en las calles y ganen algo más parecido al sueldo mínimo. En otras palabras, los salarios altos de los choferes parecen una renta que ellos están percibiendo por la forma particular en que opera el sistema de transportes en Santiago. Si con un sistema distinto los choferes recibieran un sueldo fijo mensual, no compitieran en las calles y el sueldo se redujera hasta el promedio de un asalariado en Santiago, entonces el gasto en remuneraciones bajaría en más de $\$ 20.000$ millones al año, o cerca de 30 millones de dólares.

En conclusión, una estimación conservadora es que las rentas totales, resumidas en el Cuadro $\mathrm{N}^{\circ} 3$, suman 65 millones de dólares al año. El 46\% (aproximadamente 30 millones de dólares) se la dejan para sí los

${ }^{33}$ La escasa rentabilidad de los recorridos de baja densidad no es sostenible, por lo que algún costo tiene que reducirse para que el negocio sea sustentable. Aquí supondremos que en estos recorridos el pago de planilla es igual a cero. 
CUADRO N ${ }^{\circ}$ 3: $\quad$ LAS RENTAS DEL TRANSPORTE PÚBLICO

\begin{tabular}{lcc}
\hline & $\begin{array}{c}\text { Renta } \\
\text { (en millones de dólares) }\end{array}$ & $\begin{array}{c}\text { Renta } \\
\text { (en porcentaje) }\end{array}$ \\
\hline Dueños de micro & 22 & 34 \\
Titulares de concesiones & 13 & 20 \\
Choferes & 30 & 46 \\
Total & 65 & 100 \\
\hline
\end{tabular}

Fuente: Cálculos propios a partir del Cuadro $\mathrm{N}^{\circ} 2$ y del Recuadro $\mathrm{N}^{\circ} 1$.

choferes, que reciben una remuneración inusualmente alta. Un tercio (22 millones de dólares) lo perciben los empresarios dueños de recorridos de alta rentabilidad, y el restante 20\% (14 millones de dólares) es para los titulares de las concesiones.

Hay dos formas de entender las rentas. Una es interpretarlas como el monto que debería pagársele a un agente para que no obstaculice las reformas del sector. Pero, por otro lado, si una reforma se vuelve políticamente viable, esas rentas son recursos disponibles para aumentar las inversiones en el sector o disminuir el pasaje. Por ejemplo, si con una reforma fuera posible pagarles un sueldo fijo a los choferes equivalente al salario promedio de Santiago, entonces sería posible disminuir el pasaje hasta que los ingresos del sector disminuyan en 30 millones de dólares al año. $\mathrm{O}$, con menores sueldos, los empresarios deberían estar dispuestos a invertir hasta 30 millones de dólares adicionales al año con las mismas tarifas de hoy para mejorar la calidad del servicio. Estas inversiones podrían ser en infraestructura o en mejores buses. Todo ello supone, por supuesto, que una reforma así es técnicamente viable y políticamente factible. Esto lo exploramos a continuación.

\section{UN MERCADO LIBRE NO PUEDE SER COMPETITIVO}

Hoy la regulación es un híbrido entre competencia y exclusividad. Las empresas compiten por el mercado en la licitación, pero también compiten en el mercado en aquellas calles donde los recorridos se superponen, de modo que buses de distintas asociaciones y propietarios se reparten los mismos pasajeros. ¿Es éste el sistema óptimo? Algunos piensan que una 
alternativa es liberalizar completamente la entrada y las tarifas. Para no repetir lo que ocurrió durante los años ochenta, la autoridad simplemente debería ser más enérgica e impedir que se forme un cartel de operadores.

Pero la liberalización no resolvería los problemas del sector. Por varias razones los mercados de transporte urbano no son competitivos. A continuación explicamos por qué falla el mercado y, armados con este diagnóstico, proponemos los lineamientos generales que debería seguir una reforma.

\subsection{La competencia en precios y calidad es tenue}

La competencia en precios y calidad entre empresas de transporte urbano no es tan intensa como en otras industrias, aun sin colusión entre operadores. Ya vimos que durante la liberalización del mercado en el Santiago en los años ochenta, las tarifas aumentaron considerablemente. En Inglaterra, las tarifas aumentaron $17 \%$ entre 1986 y 1994, justo después de su reforma liberalizadora ${ }^{34}$. Klein et al. (1997) señalan que "ha sido muy infrecuente que las empresas compitan ofreciendo tarifas más bajas" 35 . Glaister (1998) concluye lo mismo, y además enfatiza la sorprendente homogeneidad de tarifas en Gran Bretaña ${ }^{36}$. La misma falta de competencia en precios se ha documentado en el mercado de taxis cuando éstos han sido liberalizados ${ }^{37}$.

¿Por qué no se compite intensamente en precios? La respuesta, formalizada por Fernández y De Cea (1990) y Gómez-Lobo (2004), es la siguiente. Supongamos que hay dos tipos de micros, las que cobran caro y las que cobran barato, y examinemos la decisión de un pasajero que debe escoger entre tomar la micro que ya llegó al paradero, pero que cobra caro, o seguir esperando que pase una que cobra barato. El beneficio de esperar es la posibilidad incierta de que pase una micro barata (es posible que también la siguiente micro cobre caro). El costo cierto es dedicar tiempo a esperar. Se puede demostrar que el costo de espera y la incertidumbre de no saber si la siguiente micro será cara o barata hacen que al pasajero le convenga subirse a la micro cara pero que ya llegó al paradero, a no ser que las micros baratas sean abundantes y cobren apreciablemente menos. Por eso, en general la demanda que enfrenta una micro que ya llegó al

\footnotetext{
${ }^{34}$ White (1995) citado en Klein et al. (1997).

${ }^{35}$ Klein et al. (1997), p. 68. La traducción al castellano es nuestra.

${ }^{36}$ Cabe señalar que en el caso británico ningún autor señala la colusión como posible explicación.

${ }^{37}$ Frankena y Paulter (1986) y Teal y Berglund (1987) citados en Klein et al. (1997).
} 
paradero no es muy sensible a la tarifa que cobra. En ese caso los operadores tienen pocos incentivos para competir con precios más bajos: el único efecto de cobrar tarifas bajas es recibir menos pasajeros que los que habrían tomado de todos modos. Siendo así, nadie cobra tarifas bajas.

Por cierto, la magnitud del efecto dependerá del costo de espera promedio de los pasajeros y de su sensibilidad frente a las diferencias de tarifas — la así llamada elasticidad-precio de demanda- ${ }^{38}$. Si el costo de espera es alto, la demanda debiera ser menos sensible. Se podría pensar que el costo de esperar no es muy alto porque el ingreso de las personas que utilizan micros no es alto. Pero tal conjetura probablemente es incorrecta, y para demostrarlo tomemos un caso extremo.

Supongamos una persona que gana $\$ 650$ pesos la hora, o sea el salario mínimo. Marcial Echenique (2004) advierte que, según los estudios de transporte, las personas valoran su tiempo de traslado en aproximadamente un $50 \%$ de su ingreso por hora ${ }^{39}$. Esto significa que el costo del tiempo de espera de una persona que gana el salario mínimo es aproximadamente $\$ 325$ por hora o $\$ 5,4$ por minuto. Si esta persona deja pasar un bus, tiene que esperar apenas cuatro minutos al siguiente bus (el tiempo promedio de espera en Santiago), con la certeza de que la siguiente micro será la barata, y ya incurrió un costo de $\$ 21,6$. Y si la probabilidad de que pase un bus barato es 0,5 , éste tendría que cobrar a lo menos $\$ 43,2$ menos para que la espera valga la pena. Naturalmente, el monto es mayor para inducir a esperar a quienes ganan más que el salario mínimo. Por ejemplo, el Cuadro $\mathrm{N}^{\circ} 4$ muestra que una persona que gana $\$ 200.000$ al mes, esperará sólo si, teniendo la certeza de que el siguiente bus será barato, la tarifa baja es alrededor de \$39,3 menos que la tarifa alta. Estas magnitudes son apreciables si se toma en cuenta que el pasaje cuesta alrededor de $\$ 300$.

Pero aún hay más. Tal como lo observan Paredes y Baytelman (1996), mientras más homogéneas sean las tarifas, menor será la sensibilidad de la demanda ante una baja unilateral de precios de un bus dado. ¿Por qué? Si las tarifas son homogéneas, la disminución unilateral de un bus apenas altera la probabilidad percibida por un pasajero que espera en un paradero a que el próximo bus sea barato. La última línea del

${ }^{38}$ La elasticidad-precio de la demanda es un número puro que indica en cuánto varía la cantidad demandada del bien cuando cambia su precio. Por ejemplo, si la elasticidad-precio de la demanda por viajes en micro fuera $-0,02$, entonces el número de viajes en micro aumenta en $2 \%$ cuando el pasaje aumenta en $10 \%$.

39 Este porcentaje probablemente subestima el valor del tiempo de espera en un paradero, porque proviene de estudios que miden la valoración del tiempo de las personas que ya están dentro de un vehículo. El valor del tiempo de espera en un paradero puede llegar a ser varias veces el valor de tiempo dentro del vehículo. 
CUADRO $\mathrm{N}^{\circ}$ 4: $\quad$ DIFERENCIA DE TARIFAS NECESARIA PARA QUE VALGA LA PENA ESPERAR CUATRO MINUTOS POR UNA MICRO BARATA (en pesos)

\begin{tabular}{lccccc}
\hline & \multicolumn{5}{c}{ Ingreso mensual y por hora } \\
\cline { 2 - 6 } $\begin{array}{l}\text { Probabilidad de que el } \\
\text { siguiente bus sea barato }\end{array}$ & $\$ 110.000$ & $\$ 150.000$ & $\$ 200.000$ & $\$ 250.000$ & $\$ 300.000$ \\
& $\$ 5,4$ & $\$ 7,4$ & $\$ 9,8$ & $\$ 12,3$ & $\$ 14,7$ \\
\hline 1,0 & 21,6 & 29,5 & 39,3 & 49,1 & 58,9 \\
0,5 & 43,2 & 58,9 & 78,5 & 98,2 & 117,8 \\
0,1 & 216,0 & 295,0 & 393,0 & 491,0 & 589,0 \\
\hline
\end{tabular}

Notas:

(1) El Cuadro muestra la diferencia de tarifas entre micros caras y baratas que sería necesaria para que valga la pena esperar cuatro minutos en vez de subirse de inmediato a una micro cara.

(2) Para obtener el ingreso por hora se ha supuesto que cada mes tiene 4,2 semanas y que se trabaja 40 horas a la semana.

Fuente: Cálculos propios.

Cuadro $\mathrm{N}^{\circ} 4$ indica la diferencia de tarifas necesaria si la probabilidad de que el siguiente bus sea barato es 0,1 . Aun para quien gana el salario mínimo, esta diferencia es apreciable: $\$ 216$. Y si la persona gana $\$ 300.000$ al mes, la diferencia de tarifas es mucho mayor que lo que cuesta un pasaje: $\$ 589$ contra alrededor de $\$ 300$.

Algo análogo sucede con la calidad del servicio. En viajes urbanos cortos es posible que a la mayoría de los pasajeros les interese más el tiempo que pasarán esperando en el paradero y trasladándose que la calidad del bus, aun cuando todos estarían dispuestos a pagar más por aumentar la calidad de todo el sistema. En consecuencia, puede ser que la demanda que enfrenta un operador sea menos sensible a la calidad del servicio que en otras industrias ${ }^{40}$. Y a todo esto se suma la aparente facilidad con que los empresarios logran concertarse, tal como lo sugiere la experiencia de Chile y de otros países. La conclusión es que en un mercado libre probablemente la competencia termine en precios altos y calidad deficiente.

${ }^{40}$ Esto puede ser muy distinto en la industria de transporte interurbano, porque los viajes son más largos y de mayor valor. En ese caso, los pasajeros probablemente son más sensibles a la calidad de servicio. Además, en ese mercado los viajes son de punto a punto, sin paradas intermedias, y es posible implementar horarios en el terminal. Esto genera certidumbre y elimina el tiempo de espera en un paradero y así los pasajeros pueden optar entre operadores que compiten solamente por precio y calidad. 


\subsection{El porcentaje por boleto cortado y la "guerra por el centavo"}

Vimos que uno de los principios determinantes de la clientela de un bus será el orden de llegada a los lugares donde se concentran pasajeros. El empresario quiere sacarle la máxima rentabilidad posible a su máquina y, para ello, debe darle estímulos adecuados al chofer. Podría pagarle un sueldo fijo mensual, una suma fija por día trabajado o por kilómetro recorrido o un bono para premiar el cumplimiento de los horarios. En Santiago se les paga un porcentaje de cada boleto cortado. Esta fórmula tiene una ventaja para el empresario: el chofer se esmera por recoger el mayor número de pasajeros.

Pero también tiene múltiples desventajas, tanto para los pasajeros como para el resto de la vida de la ciudad, pues genera lo que los colombianos bautizaron como "la guerra por el centavo". Esta competencia suele amenazar la vida de los peatones, porque los choferes no toman en cuenta la inseguridad que imponen a los peatones, a los automovilistas y a los mismos pasajeros de las micros. El comportamiento tradicional es no respetar las normas del tránsito. Al chofer le conviene acelerar a fondo en la mitad de la cuadra para adelantarse a otra micro y después frenar bruscamente al llegar al paradero (o, si el pasajero está parado a mitad de la cuadra, frenar bruscamente ahí mismo). Y eso es precisamente lo que hacen, con el consiguiente deterioro de la seguridad de tránsito. Las cifras de accidentes presentadas en la sección anterior hablan por sí solas: en promedio, cada bus participa en un accidente al año.

Es importante notar que, si bien una tarifa más baja modera el incentivo para competir por tomar pasajeros, no lo elimina totalmente. Basta que un bus tenga alguna capacidad ociosa para que le sea rentable a un empresario (y por ende a un chofer) competir por tomar pasajeros adicionales. Hay amplia evidencia sobre este punto. Por ejemplo, GómezIbáñez (2003) señala que en Sri Lanka ocurrieron los mismos problemas - carreras, inseguridad, distorsión en las frecuencias - incluso en períodos en que las tarifas estaban rezagadas con respecto a los costos de operación. Solamente cuando los buses van llenos en todo momento no se compite por pasajeros en las calles. Pero obviamente una situación así tampoco sería conveniente, porque se viajaría incómodo en buses atestados.

La competencia por tomar pasajeros también distorsiona las frecuencias y los recorridos, reduciendo la eficiencia del sistema de transporte urbano en general y la calidad del servicio ${ }^{41}$. Un ejemplo son las paradas

${ }^{41}$ Banco Mundial (2000), p. 102, ilustra con ejemplos de varias ciudades del mundo las distorsiones que se señalan a continuación. 
para recoger pasajeros en cualquier punto de la ruta, congestionando más de lo necesario y reduciendo la velocidad promedio del transporte privado y público. Otro son las estrategias que utilizan los choferes, aun de la misma línea, para obstruirse cuando varios competidores convergen simultáneamente en las vías donde espera la mayoría de los pasajeros. En la Alameda, por ejemplo, donde se permiten dos filas de buses, hay choferes que tratan de impedir que el competidor entre en la primera fila y recoja pasajeros.

Similar es el fenómeno llamado "apretar" (head running en inglés). Un chofer disminuye su velocidad para acumular pasajeros y luego trata de mantenerse justo por delante de su competidor si aparece uno. Ello distorsiona las frecuencias, porque hay momentos en que no pasan micros y luego aparecen varias ${ }^{42}$. También produce distorsiones al final de cada recorrido, cuando el chofer debe recuperar el tiempo perdido por haber "apretado" al comienzo ${ }^{43}$. En estos casos los choferes no recogen clientes hacia el final del recorrido y aceleran para llegar a tiempo a la garita, con el consiguiente peligro de accidentes ${ }^{44}$.

La remuneración por boleto cortado también afecta el tamaño que puede alcanzar una empresa de transportes. Cuando el chofer cobra puede robar parte del pasaje ${ }^{45}$. “Me lleva por cien?”, piden muchos pasajeros, y al chofer le conviene decir que sí. Este bono informal que se autoasignan los choferes aumenta el salario promedio y reduce la rentabilidad del empresario. Pero, además, genera fuertes deseconomías de escala en la administración de una flota porque el costo de supervisar choferes crece con su número ${ }^{46}$. Un experto del sector estima que, como regla general, un empre-

${ }^{42}$ Según fuentes de la industria, la competencia induce a que las distintas líneas elijan aleatoriamente la hora de salida del terminal en la mañana. Si una línea sabe que su competidor saldrá a la misma hora todos los días, puede aprovechar esta información para salir justo antes que él y aumentar su tasa de ocupación.

${ }^{43}$ Las asociaciones de cada recorrido controlan el despacho y la hora de llegada. A los choferes que no cumplen el recorrido en el tiempo establecido se les suele cobrar una multa.

${ }^{44}$ Otro fenómeno que puede ocurrir (aunque en Santiago es menos frecuente) es que los buses no completen el recorrido. Si hacia el final del recorrido quedan pocos pasajeros, o los transfieren a otro bus del mismo recorrido o los dejan ahí mismo y dan la vuelta.

${ }^{45} \mathrm{Ha}$ sido imposible introducir el cobrador automático, porque a los pasajeros no les gusta (tienen que subirse con sencillo al bus), y los micreros lo rechazan porque aumenta los tiempos de embarque de pasajeros.

${ }^{46}$ Hay otro factor que también contribuye a mantener esta estructura industrial. La propiedad atomizada tiene ventajas en cuanto a la responsabilidad legal frente a accidentes u otras demandas judiciales. Un propietario es responsable legalmente hasta un monto equivalente al capital invertido. Al distribuir la propiedad entre familiares se reduce el monto con el cual debe responder en caso de indemnización. 
sario es incapaz de administrar más de 25 buses ${ }^{47}$. Incluso en aquellas empresas más grandes, es común encontrarse con que la administración se comparte entre familiares y cada miembro administra un subconjunto de los buses.

Finalmente, el sistema de cobro actual también es inseguro para los propios choferes. El importe de los pasajes se acumula en la caja del bus, un blanco seguro para asaltantes. Los frecuentes atracos violentos preocupan al gremio y a las autoridades.

\subsection{La descoordinación de los recorridos}

Varios autores han señalado que en un mercado libre de transporte urbano se desaprovechan las economías que pueden materializarse cuando se integran los diferentes servicios de una red de transporte (Nash, 1988; Evans, 1987). Un ejemplo sirve para ilustrar la descoordinación que puede ocurrir $^{48}$. Supongamos que un pasajero viaja temprano en la mañana, cuando la demanda es baja, pero vuelve a medio día cuando hay más pasajeros. Puede ser que a ningún operador le sea rentable ofrecer el servicio de la mañana, ya que hay muy pocos pasajeros. Sin embargo, al mediodía el ingreso del pasajero adicional podría más que compensar el déficit de la mañana. Por lo tanto, en un sentido global sería socialmente beneficioso que se ofrezca el servicio de la mañana, ya que los pagos totales que haría el pasajero (pasaje de la mañana y la tarde) son más que suficientes para pagar costos del servicio adicional. Sin embargo, en un sistema de recorridos independientes, el operador de la mañana seguramente perdería plata porque el pasajero seguramente volvería al medio día con otro operador.

La literatura especializada también ha señalado que un sistema de transporte competitivo genera insuficiente información sobre horarios, posibilidades de intercambio de rutas, modos de transporte e insuficiente integración tarifaria. La desintegración de la red de transporte puede significar que los costos de operar el sistema en su conjunto sean más elevados que lo que las condiciones económicas y tecnológicas permiten. Las dificultades para negociar acuerdos entre operadores independientes, que en el caso de la integración tarifaria y de recorridos presupone recaudar centralizadamente y luego repartir los ingresos totales entre ellos, son el obstáculo

\footnotetext{
${ }^{47}$ Entrevista con Pablo Uribe, ex profesional del MOPTT (Ministerio de Obras Públicas y Transporte y Telecomunicaciones), 21 de enero de 2002.

${ }^{48}$ Este ejemplo fue tomado de Gómez-Ibáñez y Meyer (1997).
} 
principal para que estos servicios se materialicen en un mercado como el que opera actualmente en Santiago ${ }^{49}$.

Hay evidencia de que reordenando e integrando la red de transporte se podrían ahorrar costos de operación. Vivanco (2002) utilizó información de la encuesta del transporte público de 1997 e hizo un ejercicio con el eje troncal Alameda-Providencia-Apoquindo entre las 7 y las 9 de la mañana. De los 147 recorridos con más de cinco paraderos en este eje, comparó los costos totales de operación y capital en las condiciones actuales de servicio con una alternativa en que cada recorrido se divide en tres segmentos: uno de acercamiento hacia el eje central operado por un bus con capacidad equivalente a la de los actuales buses; otro de difusión que lleva a los pasajeros desde el eje central hacia la periferia; y un segmento correspondiente al eje central Alameda-Providencia-Apoquindo. Con un modelo de programación lineal escogió tecnologías para cada segmento con el fin de minimizar los costos de operación de todo el sistema. El resultado fue que los costos de operación y capital se minimizaban utilizando buses convencionales en los segmentos de acercamiento y difusión, y buses articulados de tres secciones de gran capacidad para operar en el eje central. Los costos de esta alternativa eran $47 \%$ más bajos que los costos del sistema actual.

A pesar de que algunos de sus supuestos son extremos, el estudio de Vivanco (2002) sugiere que existen economías desaprovechadas en la red de transporte de superficie en Santiago. Para que estos ahorros se materialicen, es necesario integrar los distintos recorridos mediante un diseño optimizado de la red de transporte, construir infraestructura de transferencia e introducir un sistema de integración tarifaria. Ninguno de estos cambios puede ocurrir sin una intervención activa de las autoridades.

\subsection{Las veredas no tienen dueño $0^{50}$}

Las veredas donde los pasajeros esperan son bienes de acceso abierto que cualquier operador (incluso informal) puede aprovechar para tomar pasajeros. Según Klein et al. (1997), esta característica causa el siguiente problema. Existe demanda por transporte público cuando previamente existe un servicio regular con horarios programados, paraderos y otros

${ }^{49}$ La integración horizontal mediante fusiones, por ejemplo, sería una solución de mercado a estos costos de transacción. Sin embargo, las mismas razones que mantienen la propiedad atomizada conspiran en contra de una consolidación que permitiría integrar la red privadamente.

${ }^{50}$ Agradecemos a José Gómez-Ibáñez por habernos informado sobre este argumento que aparece en el libro de Klein et al. (1997). 
elementos para operar el servicio. En estos mercados, una empresa debe invertir en estas características, posiblemente durante algunos meses a pérdida, para inducir a que la gente utilice el transporte público. Pero si una empresa hace esta inversión y genera la demanda por el servicio, después puede ingresar un competidor (autorizado o informal) y quitarle la clientela que espera en la vereda. Porque son públicas las veredas, y porque no puede evitar que otros operadores recojan pasajeros, la empresa no puede recuperar su inversión. Entendiendo esto de antemano, la empresa no hace la inversión, no se genera la demanda y el mercado de transporte público desaparece.

Cuando la demanda es suficientemente alta y no es tan sensible a la existencia previa de un servicio regular y de alta calidad (por ejemplo, en una zona urbana, como el centro de Santiago), el mercado de transporte público no desaparece, pero se estanca en un equilibrio de "bajo nivel", esto es, baja calidad y seguridad del servicio. Si bien la gran mayoría de los usuarios preferiría un sistema de mayor calidad, regularidad y seguridad, ninguna empresa tiene el incentivo de mejorar unilateralmente los recorridos. Si una empresa hiciera una inversión con tal fin, el efecto agregado en la calidad y seguridad de la industria sería pequeño, y no generaría un aumento significativo de la demanda por viajes. Además, los usuarios seguirían subiéndose al primer bus que llegue al paradero. La empresa que hizo la inversión no experimentaría un aumento significativo de su demanda y no lograría recuperar su inversión.

Un argumento como el anterior podría explicar por qué no se desarrollan servicios de mayor calidad en Santiago ${ }^{51}$. De hecho, hay evidencia anecdótica al respecto. En los años ochenta una empresa intentó pagarles un sueldo fijo a los choferes. El resultado fue que perdió muchos pasajeros y pronto tuvo que volver al porcentaje por boleto cortado.

El equilibrio de bajo nivel también limita la demanda agregada del sistema de transporte público en Santiago. Es probable que un sistema más ordenado, con mejor calidad y seguridad, induzca un mayor uso de este medio de transporte. Luego de la reforma del sistema de transporte por superficie en Bogotá, que describimos líneas abajo, el aumento de la calidad, rapidez y seguridad del servicio generó un aumento significativo de usuarios del sistema público (Hidalgo-Guerrero, 2001).

${ }^{51}$ Este argumento ayuda a explicar las diferencias que hay entre la industria de transporte interurbano y la de transporte urbano. En el interurbano los clientes viajan de un punto a otro (no están repartidos a lo largo de todo un recorrido), por lo que es posible congregarlos en un terminal privado sin que otros operadores se los lleven. En este caso las empresas quieren invertir en terminales, buses de alta calidad, servicio seguro y horarios. 
Hay dos medidas para evitar el equilibrio de bajo nivel que genera la propiedad pública sobre las veredas. Klein et al. (1997) proponen un sistema de derechos transables sobre los espacios de veredas, como una forma de aprovechar los beneficios de la competencia sin los problemas que genera la propiedad pública de esta infraestructura. Con este esquema, sólo la empresa dueña de los derechos de algún espacio de vereda tiene el derecho de recoger pasajeros ahí. La fiscalización para evitar que otras empresas recojan pasajeros donde no tienen derechos sobre las veredas podría hacerse mediante cámaras de video instaladas en las calles de la ciudad.

La segunda solución es darle exclusividad de servicio a un operador y fiscalizar que no entren operarios informales. Para evitar el abuso de la posición dominante de la que gozaría el operador exclusivo, necesariamente hay que licitar el derecho de operar la zona. En Santiago existe un sistema de licitación de recorridos, pero salvo en las áreas cercanas a los puntos de partida y llegada de los recorridos, no hay exclusividad. Muchos recorridos se superponen y las empresas compiten por pasajeros en las veredas públicas de la ciudad. La exclusividad es un punto clave de cualquier reforma al sistema actual.

\subsection{Congestión y otros efectos secundarios}

Por último, incluso sin ninguna de las fallas mencionadas más arriba, en este mercado hay una externalidad básica: los operadores privados no tomarán en cuenta que sus buses congestionan y contaminan. En los países desarrollados, el transporte público es visto como una solución a los problemas de congestión y de contaminación atribuibles al enorme parque de vehículos privados. Pero en los países en vías de desarrollo, donde la mayoría de los viajes se hacen en bus, éstos también son parte del problema. En Santiago, la Encuesta Origen Destino de 2001 indica que el $42 \%$ de los viajes de un día laboral se hace en bus ${ }^{52}$.

${ }^{52}$ En todo caso, la participación del transporte público ha caído: en 1991, el 60\% de los viajes se hacían en bus. El otro lado de la moneda es que el automóvil aumentó su participación de 18,5\% de los viajes en 1991 a 38,1\% en 2001. Como se discute en el trabajo de Enrique Cabrera, Carlos Díaz y Ricardo Sanhueza (2004), estas cifras concuerdan con una tendencia natural del desarrollo económico: a medida que aumenta el ingreso de un país las personas van optando por el automóvil como su medio de transporte. En las ciudades de los países desarrollados los viajes en transporte público (bus, metro y otros) rara vez superan el $30 \%$ de los viajes totales (NERA, 2001). 


\section{5. ¿QUÉ HACER?}

Si la liberalización de las tarifas y de la entrada no es la respuesta adecuada, ¿qué se puede hacer? La experiencia de ciudades tales como Londres, Curitiba, y recientemente Bogotá, indica que un sistema bien diseñado de concesiones asignadas en licitaciones competitivas puede lograr buenos resultados. Varios autores (v. gr., Glaister, 1998; Gómez-Ibáñez y Meyer, 1997) han destacado los logros obtenidos en Londres. Este caso es interesante, ya que se puede contrastar con la liberalización que se intentó en otras ciudades del Reino Unido. Mackie et al. (1995) evaluaron estas experiencias y concluyen que el sistema de "competencia por el mercado" mediante concesiones en Londres ha sido tanto o más exitoso que la política alternativa de liberalización y "competencia en el mercado" a la hora de reducir costos, contener los aumento de tarifas, expandir los kilómetros y proveer un sistema integrado de transporte.

En otras palabras, perseverar con la política de concesiones creada hace más de una década en Santiago es concordante con lo que se considera el estado de las artes en materia de política de transporte a nivel mundial. Pero ello no significa que el sistema deba seguir igual. Como vimos, los problemas pendientes son muchos, y serios. A continuación señalamos los elementos más importantes de la reforma necesaria ${ }^{53}$.

\subsection{Separar el cobro de pasajes y la operación de los recorridos}

Varios problemas que aquejan al transporte público en Santiago se pueden solucionar si los ingresos de los operadores continúan dependiendo del número de pasajeros transportados. Actualmente los operadores reciben su ingreso por "boleto cortado", lo que los incentiva a correr por las calles, distorsiona las frecuencias y causa otros males que ya discutimos. Una posibilidad obvia sería aplicar más rigurosamente las leyes del tránsito, imponiendo multas proporcionales al costo social causado por la violación de estas normas. Sin embargo, mientras persistan los incentivos actuales, aplicar las leyes de tránsito sería nadar contra la corriente. Mucho mejor sería cambiar los incentivos, para eliminar el estímulo económico que induce a violar las leyes. ¿Cómo hacerlo?

La alternativa consiste en separar el cobro de los pasajes de la operación de los recorridos y pagarles a los operadores un monto fijo

${ }^{53}$ Es importante enfatizar que las propuestas que presentamos a continuación no son originales, sino que forman parte del consenso creciente entre los técnicos del sector. Varias de ellas son pilares fundamentales de Transantiago, el plan de reforma en que trabaja el gobierno. 
semanal o mensual por cumplir con recorridos, frecuencias y el resto de las condiciones establecidas en el contrato de concesión. Una empresa sin relación con los operadores podría vender los pasajes y posteriormente distribuir los ingresos recaudados entre los operadores, de acuerdo con los montos licitados en los contratos. Una analogía con el Metro sirve para ilustrar la idea. Las boleterías serían operadas por la empresa recaudadora y los operadores -equivalentes a los carros de metro que circulan por la red- recibirían un pago fijo periódico por hacer los recorridos. Los boletos de micro podrían venderse en quioscos de diarios, supermercados, o en oficinas cercanas a los puntos de mayor circulación de pasajeros.

A cambio de separar el cobro de la operación se obtienen varias ventajas. Al recibir un pago fijo que no depende del número de pasajeros transportados, los operadores ya no correrían por las calles y desaparecería la desenfrenada guerra por el centavo. Tampoco querrían aumentar la frecuencia de un recorrido, ni distorsionarla mediante el head running u otras practicas similares, y ya no convendría recoger pasajeros fuera de los paraderos. Y, si se cobra centralizadamente, se pueden integrar las tarifas.

Los choferes, por su parte, ya no manejarían dinero. Los asaltos terminarían y ya no sería necesario controlarlos para que no se roben parte de los pasajes. Desaparecería así uno de los principales obstáculos que actualmente impiden que se formen empresas más grandes con una gestión más sofisticada. La función de los choferes cambiaría y ya no sería necesario pagarles un bono por su capacidad y habilidad para competir en las calles, con la consiguiente reducción de los costos del sistema de transporte. Los beneficios de cambiar el sistema de pagos se pueden materializar aun si los micreros siguieran recibiendo rentas. Por ejemplo, aun si la licitación de recorridos sigue siendo poco competitiva, el sólo hecho de pagarles un monto fijo a los operadores elimina la guerra por el centavo.

Una posible objeción a remunerar con un pago fijo es que al operador le convendría disminuir las frecuencias y los pasajeros transportados. Sus costos serían menores mientras que el ingreso sería el mismo. Pero este problema tiene fácil solución. Hay sistemas de monitoreo electrónico de bajo costo mediante aparatos de posicionamiento geográfico (o GPS) instalados en cada vehículo que permiten observar la frecuencia, velocidad y número de paradas de los buses. Un organismo especial —el Centro de Control de Buses, por ejemplo- sería el encargado de fiscalizar que las frecuencias y otras condiciones contractuales efectivamente se cumplan y de llevar la cuenta de los kilómetros recorridos por cada operador. El sistema de pago debe diseñarse de forma de aumentar o disminuir este pago de acuerdo con el cumplimiento de la calidad de servicio establecida en el contrato. 


\subsection{Optimizar e integrar la red de transportes}

Cuando se introdujeron las concesiones licitadas a comienzos de los años noventa, se mantuvieron intactos los recorridos existentes. Por eso hay muchas oportunidades para reorganizar la red y optimizarla. Por ejemplo, en las arterias principales de la ciudad, donde la densidad de pasajeros es alta, podría ser más eficiente dar una concesión exclusiva para buses de gran capacidad que hagan estos recorridos continuamente. Los recorridos que vienen de la periferia ya no entrarían a las arterias principales, sino que dejarían a los pasajeros junto al metro o a los buses de gran capacidad. Luego los buses de alta capacidad transportarían a los pasajeros por la arteria hasta su destino final, o hasta otro punto de intercambio donde proseguirían su viaje en otro servicio.

Por ejemplo, hoy una persona que vive en Maipú y viaja desde Pudahuel hasta Vitacura puede tomar un bus que sale de Pudahuel, pasa por la Alameda (o Merced), sigue por Providencia y finalmente toma Vitacura. Como todos los servicios hacen estos recorridos de punta a punta, en su mayoría pasando por el centro, los recorridos se superponen y congestionan. La alternativa es que el pasajero tome un bus de acercamiento en Pudahuel que lo deje en Pajaritos; luego se cambie al metro o a un bus de alta capacidad que opere el eje Pajaritos-Alameda-Providencia-Apoquindo; y luego transborde en Las Condes o Providencia a otro servicio periférico que lo lleve hasta Vitacura.

Con el esquema propuesto se necesitarían menos buses en las arterias principales de la ciudad, que se descongestionarían, pero el número de transbordos por viaje aumentaría bastante. En general, a las personas les desagrada transbordar porque es parte importante del costo total (monetario y psíquico) de un viaje. Pero aun así es probable que los pasajeros estén más que dispuestos a transbordar si no tienen que pagar más y el tiempo de viaje disminuye $\mathrm{e}^{54}$.

Esto implica que la integración de las tarifas debe ser parte de cualquier reforma. Acortar el tiempo de viaje se logra optimizando la red y eliminando la competencia por pasajeros, porque así se reducen la congestión y los tiempos de viaje. Sin embargo, existe el riesgo de que estas mejoras sean compensadas con un aumento en el transporte privado. Para evitar esto y mientras no se introduzca la tarificación vial, sería necesario construir vías exclusivas para los buses, como la que ya existe en avenida Grecia. La evaluación de las vías exclusivas es muy positiva y, en general,

${ }^{54}$ De hecho, en varias ciudades del mundo que tienen sistemas de transporte público ejemplares, tales como Nueva York, Zurich y Londres, los pasajeros trasbordan varias veces. 
la literatura señala que este tipo de infraestructura es bastante efectivo cuando se trata de aumentar la velocidad del transporte público.

Las vías exclusivas no son la única infraestructura que debe construirse. También se necesitan estaciones de transferencia. Por la magnitud de estas inversiones y porque serían utilizadas por varios operadores distintos, es probable que se requiera que participe el Estado, ya sea como financista o como promotor de una concesión para que los privados construyan la infraestructura.

Hasta aquí hemos argumentado que la autoridad debería diseñar la red de transporte, aprovechando las posibles sinergias entre los distintos recorridos de buses. Esta optimización deberá equilibrar los beneficios del aumento de la eficiencia técnica de la red de transportes y la disminución de la congestión, por un lado, con el aumento de la molestia que los trasbordos le causan a los usuarios, por otro lado. Se podría argumentar, sin embargo, que la autoridad no tiene información suficiente para hacerlo bien. A pesar de los esfuerzos que se hagan para obtener información (en este caso, la Encuesta Origen-Destino), los técnicos del Estado jamás tendrán información suficiente sobre las preferencias de los usuarios y su comportamiento actual y potencial.

Si así fuera, la red de recorridos que se diseñe podría ser inadecuada para satisfacer la demanda efectiva de los usuarios. Por ejemplo, GómezIbáñez y Meyer (1997) señalan que en Londres, donde opera un sistema como el que proponemos, algunos operadores han criticado la excesiva rigidez de la red de recorridos y la lentitud con que las autoridades los modifican cuando cambia la demanda. Es probable que los operadores, a través de su trabajo diario en las calles y su contacto con los pasajeros, o incluso a través del ensayo y el error, conozcan mucho mejor los patrones de demanda y sepan cómo satisfacer los requerimientos cambiantes de la población.

¿Cómo se podría aprovechar esta información valiosa dentro del esquema de planificación que se propone aquí? Hay dos opciones. La primera sería incorporar algún mecanismo automático para cambiar los recorridos. Por ejemplo, por contrato de prestación de servicios, si un operador solicita un cambio de trazado o propone un nuevo recorrido, la autoridad debe aceptar la solicitud dentro de un plazo preestablecido a menos que existan razones fundadas para rechazarla. El operador podría tener derecho de apelar de la determinación de la autoridad ante una comisión de expertos elegidos de mutuo acuerdo. La segunda opción sería flexibilizar el sistema de recorridos en la periferia de la red, donde es más probable que la demanda cambie inesperadamente. Una idea interesante 
— que se incorpora en la propuesta de Transantiago_-, es que en la periferia las concesiones sean por área y no por recorrido. Así, los buses en una determinada zona geográfica (Peñalolén, La Reina y Macul, para dar un ejemplo) serían operados por una misma empresa. De esta forma se evitaría la competencia en las calles pero se permite que el operador tenga mayor flexibilidad para modificar los recorridos según su percepción de los patrones de demanda.

\subsection{Aumentar la competencia en la licitación}

Ya se demostró que las tarifas de un porcentaje significativo de los recorridos son injustificadamente altas. La explicación más plausible es que la competencia en la licitación de 1998 fue insuficiente, acaso debido a una rearticulación del cartel de operadores. ¿Cómo hacer para evitar que el sector se vuelva a "cartelizar" y lograr que la licitación sea más competitiva?

La solución más directa es que todas las licitaciones sean internacionales. Aparte de la experiencia, tecnología y métodos de gestión que podrían aportar empresas extranjeras, su participación aumentaría la competencia. Ya existe un precedente. En la última licitación de recorridos de Metrobús una empresa española se adjudicó varios recorridos. La autoridad también debería usar la institucionalidad antimonopolios sin temores. Eso fue lo que hizo el gobierno a comienzos de los noventa, cuando el gremio se opuso a la licitación, y parece que esa vez dio resultado.

\subsection{Cambiar la estructura tarifaria}

Por último, también es conveniente que los viajes más largos sean más caros. De esta forma se podría reflejar el verdadero costo que le impone cada pasajero al sistema de transportes. Y si los viajes más largos y caros se deben pagar, entonces las decisiones de lugar de residencia, estudio y trabajo se irán modificando en forma socialmente beneficiosa.

Un sistema que opera en muchas ciudades del mundo es el siguiente: la zonificación es concéntrica y los viajes que se originan o terminan en los anillos más alejados del centro son más caros. En Santiago, según el plan Transantiago, los viajes de largo alcance serán más caros que los viajes locales en las zonas periféricas o dentro de la zona central de la ciudad. Cualquier resquemor por los posibles impactos sociales que gene- 
rase un esquema como el propuesto debería enfrentarse con un subsidio directo a los afectados — por ejemplo, un bono de locomoción-.

Otra modificación importante es que las tarifas en horario punta sean más altas. El fin es financiar a los buses requeridos en el horario punta y que no circulan en el horario de valle. Un sistema de precios de ese tipo existe hoy para el metro, la electricidad, el agua y las carreteras con peajes. Su lógica es clara y no existe motivo para no introducir dicha diferenciación también en el transporte urbano.

\section{LA EXPERIENCIA DE BOGOTÁ CON TRANSMILENIO ${ }^{55}$}

Para mostrar que es posible reformar el transporte público, en esta sección contamos el caso de Bogotá, ciudad que tenía problemas similares a los de Santiago.

Tal como en Santiago, hasta poco tiempo atrás los choferes manejaban y cobraban. Y al igual que en Santiago, la guerra por el centavo era estimulada por tasas de ocupación bajas (45\% en promedio) y generaba una serie de problemas de tránsito y seguridad. La congestión era alta y los tiempos de viaje largos, aun para distancias cortas. En horas punta, la velocidad promedio podía caer a sólo 10 kilómetros por hora. Los buses eran antiguos (14 años en promedio en 1998) y de baja calidad (pues emitían demasiado ruido y contaminaban). Por ejemplo, se estima que en 1998 emitían el 70\% del material particulado proveniente de fuentes móviles.

En 1998 la alcaldía de Bogotá impulsó una reforma radical en el centro de la ciudad. El resultado fue el Proyecto Transmilenio, cuya operación comenzó en diciembre de 2000. El proyecto consiste en un sistema de corredores troncales, que son vías exclusivas para el transporte público operadas por una concesionaria privada, más una extensa red de rutas alimentadoras que permiten unir a los corredores troncales con los barrios. A la fecha existen tres corredores construidos que suman 35 kilómetros y 22 rutas de alimentación, que se extienden por 66,7 kilómetros y sirven a 40 barrios. El plan contempla llegar a 22 corredores troncales y extender la red hasta alcanzar un total de 388 kilómetros en 15 años. Una vez que el sistema esté completo, se habrán invertido 1.970 millones de dólares para transportar a cinco millones de personas al día.

El centro del sistema es la empresa pública Transmilenio S. A., que planifica, controla, gestiona y fiscaliza. Las rutas troncales y de alimenta-

55 La información que se presenta a continuación proviene de www.idu.gov.co, www.transmilenio.gov.co e Hidalgo-Guerrero (2001). 
ción se licitan a operadores privados. Se cobra mediante boletos prepagados, sistema que opera un privado bajo un contrato de concesión. La verificación del pago de los usuarios se hace a la entrada de las estaciones y los operadores, a quienes se les paga según los kilómetros que recorren y algunas variables de calidad, no cobran ni recaudan. Las tarjetas permiten integrar las tarifas de todos los recorridos de la red.

Al separar la operación de los buses del cobro de pasajes se han cambiado los incentivos de los operadores. Hoy los conductores trabajan con contrato y horarios regulares y ya no les interesa competir por pasajeros. Esto eliminó de raíz la guerra del centavo, mejorando la seguridad y la calidad del servicio.

La infraestructura de vías exclusivas, paraderos, terminales y puentes peatonales fue construida por el sector público. Existen paraderos cada 800 metros, con puentes peatonales y otros servicios. El cumplimiento de rutas y horarios se supervisa electrónicamente. Además, hay buses corrientes y expresos. Los corrientes paran en todos los paraderos y pasan cada tres minutos. Los expresos sólo paran en los paraderos principales y pasan cada cuatro minutos.

En 2001, luego de un año de operación del sistema Transmilenio, la velocidad promedio había aumentado. Por ejemplo, la velocidad promedio en dos arterias principales (la calle 80 y la avenida Caracas) era, respectivamente, de sólo 12 a 18 kilómetros por hora antes de Transmilenio. Luego del plan, había aumentado a 26,7 kilómetros por hora. Los tiempos de viaje cayeron $32 \%$, cerca de una hora diaria para el pasajero promedio.

La calidad del servicio también mejoró. En las rutas troncales circulan buses que pueden llevar hasta 180 pasajeros y tienen suspensión neumática, caja de cambios automática y motores diésel o de gas natural comprimido de última generación, que cumplen con el estándar EURO 2. En las rutas de alimentación, los buses pueden llevar hasta 80 pasajeros. A su vez, ellos han sido reacondicionados y se les fija un tope de antigüedad. El efecto más impresionante ha sido sobre los accidentes de tráfico. El Gráfico $\mathrm{N}^{\circ} 4$ muestra que el número de choques, heridos y muertos en las calles correspondientes a la red Transmilenio ha disminuido drásticamente entre 1999 (año previo a la entrada en operación del nuevo sistema) y 2001.

También ha disminuido la contaminación. El Cuadro $\mathrm{N}^{\circ} 5$ muestra la disminución de las concentraciones de tres contaminantes en el aire de Bogotá: material particulado (PM10), dióxido de azufre $\left(\mathrm{SO}_{2}\right)$ y dióxido de nitrógeno $\left(\mathrm{NO}_{2}\right)$. La columna 2 muestra la disminución entre enero de 2000 y enero de 2001. De manera similar, la columna 3 muestra la disminución entre marzo del 2000 y marzo del 2001. En cada caso, se reporta 


\section{GRÁFICO N 4: $\quad$ ACCIDENTES Y ATRACOS SEMANALES ANTES Y DESPUÉS DE TRANSMILENIO}

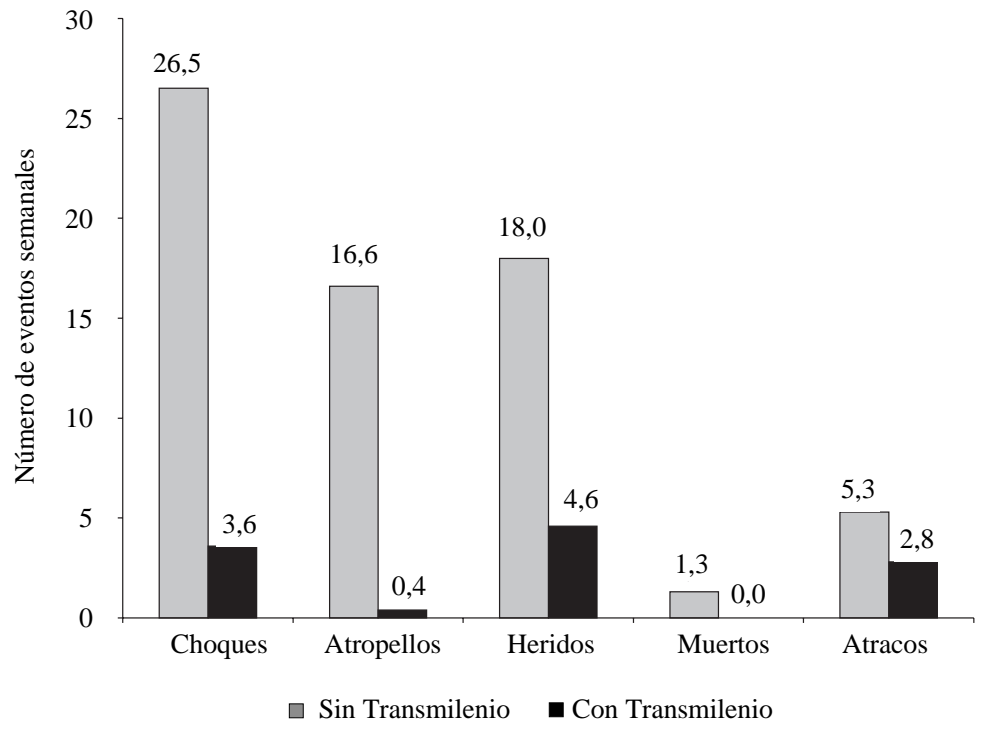

CUADRO N ${ }^{\circ}$ 5: $\quad$ DISMINUCIÓN DE LA CONTAMINACIÓN DEL AIRE DE BOGOTÁ ENTRE 2000 Y 2001

(Concentración promedio y máxima)

(1)

Contaminante

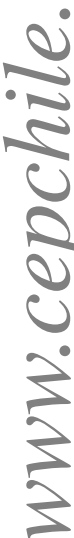

(2)

Disminución entre
enero 2000
y enero 2001

(3)

Disminución entre marzo 2000 y marzo 2001

$\begin{array}{lll}\text { Material particulado (PM10) } & 43 \% & 43 \% \\ & 54 \% & 39 \% \\ \text { Dióxido de azufre }\left(\mathrm{SO}_{2}\right) & 13 \% & 41 \% \\ & 10 \% & 46 \% \\ \text { Dióxido de nitrógeno }\left(\mathrm{NO}_{2}\right) & 31 \% & 17 \% \\ & 16 \% & 13 \%\end{array}$

Fuente: completar 
primero la caída de la cantidad promedio y a continuación la caída de la cantidad máxima del contaminante respectivo ${ }^{56}$.

El descenso de la contaminación es apreciable. El material particulado (PM10) promedio cae más de 40\% y las disminuciones del dióxido de azufre $\left(\mathrm{SO}_{2}\right)$ y del dióxido de nitrogeno $\left(\mathrm{NO}_{2}\right)$ también son apreciables. Aunque posiblemente no todos estos cambios se deban a la introducción del proyecto Transmilenio, las cifras son altamente sugerentes ${ }^{57}$.

Todos los resultados anteriores se lograron aumentando la tarifa apenas 6\%, aunque hay que notar que con un subsidio implícito. Ello porque la tarifa permite cubrir sólo los costos operacionales del sistema (incluyendo la supervisión del sistema y el sistema de recaudación), la amortización y el mantenimiento del material rodante y el mantenimiento de la infraestructura fija. El costo de capital de las inversiones en estaciones y vías segregadas lo asumió el sector público.

\section{CONCLUSIÓN}

El sistema de transporte público de Santiago tiene algunas virtudes, tales como su amplia cobertura y frecuencia. Sin embargo, también lo aquejan serios problemas de congestión, inseguridad, ineficiencia y mala calidad del servicio. Las micros también son responsables de buena parte de la contaminación del aire y acústica que padece Santiago. Estos problemas justifican una reforma de fondo.

Existe un cierto consenso a nivel técnico sobre los lineamientos generales que debería seguir dicha reforma. El Plan Transantiago, que entrará en vigencia en 2005, pretende optimizar los recorridos, integrar los modos de transporte y las tarifas, crear empresas y modernizar los buses, todo ello mediante un nuevo sistema de licitaciones, que modifique radicalmente el régimen que rige desde comienzos de la década de los noventa.

La primera pregunta respecto de una reforma es si puede mejorarse el sistema sin que aumente significativamente la tarifa de los pasajes. Este trabajo ofrece una visión cautelosamente optimista al respecto. Eliminar ciertas ineficiencias manifiestas del sistema actual permitiría brindar un mejor servicio sin incrementar los costos. Además, estimamos que hay a lo menos 65 millones de dólares en rentas que el sector genera cada año. La buena noticia es que estos recursos podrían utilizarse para financiar buses Ricardo Katz.

${ }^{56}$ Los contaminantes se explican en detalle en el Recuadro 1 de capítulo 15 de

${ }^{57}$ Parte de las caídas podrían deberse a diferentes condiciones meteorológicas, aunque no hay antecedentes al respecto. 
nuevos, o para instalar en los buses tecnologías menos contaminantes. La mala noticia es que los actuales gremios se benefician con estas rentas. Los choferes, los empresarios con recorridos de alta rentabilidad y los titulares de las concesiones se opondrán a cualquier reforma que amenace esas rentas.

La otra pregunta es cómo pagar las vías exclusivas y estaciones de transferencias, el centro de control de buses y la creación y operación de un recaudador y una cámara de compensación. Parece improbable que estos gastos se puedan financiar con el excedente del sistema, al menos con tarifas similares a las actuales. En Bogotá, gran parte de las inversiones fueron financiadas con impuestos generales (gobiernos locales) o específicos (diésel) y algunos créditos de agencias multilaterales. Aunque las tarifas se aumentaron en $6 \%$, se optó por financiar la reforma con otras fuentes.

Lo más probable es que en Santiago ocurra algo parecido. Algunos proyectos (v. gr., las estaciones de transbordo y el centro de control) podrían licitarse. Pero otros, tales como las vías exclusivas, en que parece imposible generar un negocio que pueda interesar al sector privado, probablemente deberán ser financiadas con fondos públicos.

\section{REFERENCIAS}

Balmaceda, Felipe: "La Expansión de Santiago y la Hipótesis de la 'Demanda Excesiva' por Infraestructura". Por aparecer en libro "Santiago: Dónde Estamos y hacia Dónde Vamos" (Alexander Galetovic, editor), que será publicado próximamente por el Centro de Estudios Públicos, Santiago.

Banco Mundial: Cities on the Move: A World Bank Urban Transport Strategy Review. Washington: Banco Mundial, 2000.

Bilbao, R., L. Cárcamo y L. Geisse: "El Valor Económico de la Contaminación Acústica: Un Análisis Empírico Exploratorio". Tesina de especialización, Postítulo en Economía y Finanzas para Abogados. Santiago: Facultad de Ciencias Económicas y Administrativas, Universidad de Chile, 2002.

Brueckner, J. y P. Spiller: "Economies of Traffic Density in the Deregulated Airline Industry". Journal of Law and Economics, 37, 379-415, 1994.

Cabrera, Enrique, Carlos Díaz y Ricardo Sanhueza: "La Congestión en Santiago". Por aparecer en libro "Santiago: Dónde Estamos y hacia Dónde Vamos" (Alexander Galetovic, editor), que será publicado próximamente por el Centro de Estudios Públicos, Santiago.

Conama (Corporación Nacional de Medio Ambiente): Análisis General del Impacto Económico y Social Anteproyecto de Norma de Emisión de Ruido para Buses que Presentan Servicios de Locomoción Colectiva Urbana y Rural. Conama: Unidad de Economía Ambiental, 2000. 
Cruz, C.: Transporte Urbano para un Nuevo Santiago. Santiago: Ministerio de Obras Públicas, Transportes y Telecomunicaciones, 2002.

Dourthé, A., H. Malbrán y M. Wityk: "Regulación del Transporte Público de Superficie: La Experiencia de Santiago de Chile". Mimeo, SECTRA, 2000.

Echenique, Marcial: "Las Vías Expresas Urbanas. ¿Qué tan Rentables Son?” Por aparecer en libro "Santiago: Dónde Estamos y hacia Dónde Vamos" (Alexander Galetovic, editor), que será publicado próximamente por el Centro de Estudios Públicos, Santiago.

EMG Consultores: "Análisis de la Estructura Tributaria del Transporte Público y de Carga". Informe final, Ministerio de Obras Públicas, Transportes y Telecomunicaciones, 2002.

Evans, A.: "A Theoretical Comparison of Competition with Other Economic Regimes". Journal of Transport Economics and Policy, 21, 7-36, 1987.

Fernández, J. E. y J. de Cea: "Características de Equilibrio en un Sistema de Transporte Público Urbano bajo Condiciones de Libre Competencia". Revista de Ingeniería de Sistemas, 7, 27-43, 1990.

Fernández, D.: “The Modernization of Santiago's Public Transport: 1990-1992”. Transport Review, 14, 167-185, 1994.

Frankena, M. y P. Paulter: "Taxicab Regulation: An Economic Analysis". Research in Law and Economics, 9, 129-165, 1986.

Glaister, S.: "Desregulación y Privatización". En G. de Rus y C. Nash (eds.), Desarrollos Recientes en Economía del Transporte. Washington: Instituto del Desarrollo Económico del Banco Mundial y Editorial Civitas S. A., 1998.

Gómez-Ibáñez, J. A.: Regulating Infrastructure: Monopoly, Contracts and Discretion. Cambridge: Harvard University Press, 2003.

Gómez-Ibáñez, J. A. y J. R. Meyer: "Alternatives for Urban Bus Services: An International Perspective on the British Reforms". Transport Reviews, 17, 17-29, 1997

Gómez-Lobo, A.: "Why Competition Does Not Work in Urban Bus Markets: Some New Wheels for Old Ideas". Mimeo, Universidad de Chile, 2004.

Hidalgo-Guerrero, D., "Transmilenio: El Sistema de Transporte Masivo en Bogotá". Mimeo, Transmilenio S. A., 2001.

Katz, Ricardo y Conama:

Klein, D. B., A.T. Moore y B. Reja: Curb Rights: A Foundation for Free Enterprise in Urban Transit. Washington: Brookings Institution Press, 1997.

Mackie, P., J. Preston y C. Nash: "Bus Deregulation: Ten Years On”. Transport Reviews, 15, 317-339, 1995.

Malbrán, H.: "El Programa de Medidas Inmediatas y la Política de Prioridad de Transporte Público". Trabajo presentado en el X Congreso Chileno de Ingeniería de Transporte, 2001.

Ministerio de Obras Públicas, Transportes y Telecomunicaciones: Estudio de Demanda del Sistema de Transporte Público de Superficie de Santiago 1997. Santiago: Secretaría Regional Ministerial de la Región Metropolitana, 1997.

Nash, J.: "Integration of Public Transport: An Economic Assessment". En J. S. Dodgson, y N. Topham (eds.), Bus Deregulation and Privatization: An International Perspective. Aldershot: Avebury, 1998.

NERA (National Economic Research Associates): Models for the Provision, Regulation and Integration of Public Transport Services: A Final Report for the Public Transport Partnership Forum of Ireland. Londres: National Economic Research Associates, 2001. 
Paredes, R. y Y. Baytelman: "Urban Public Transport Deregulation: The Chilean Experience". Estudios de Economía, 23, 193-210, 1996.

Sanhueza, R. y R. Castro: "Conduciendo el Transporte Público: La Licitación de Recorridos en Santiago". Perspectivas en Política, Economía y Gestión, 3, 217-230, 1999.

Teal, R. y M. Berglund: “The Impacts of Taxi Deregulation in the USA”. Journal of Transport Economics and Policy, 21, 37-56, 1987.

Vivanco, J. L.: "Estimación de los Ahorros Financieros Mínimos de la Optimización del Sistema de Transporte Urbano". Seminario para optar al título de Ingeniero Comercial mención Economía. Santiago: Facultad de Ciencias Económicas y Administrativas, Universidad de Chile, 2002.

White, P. R.: "Deregulation of Local Bus Services in Great Britain: An Introductory Review". Transport Reviews, 15, 185-209, 1995. 